\title{
Hipotermia perioperatoria
}

\section{Perioperative hypothermia}

\author{
Renato Chacón Abba'
}

\begin{abstract}
Perioperative hypothermia is a common complication of general anesthesia, but it can also occur in patients undergoing regional anesthesia. It significantly increases perioperative morbidity and mortality. Complications such as increased incidence of surgical site infection, delayed healing, coagulation abnormalities, increased surgical bleeding, perioperative cardiac events, decreased metabolism of drugs involved in anesthesia and a great discomfort in the immediate postoperative period (due to shivering), have been identified. The decrease in the patient's core temperature is due to a combination of physiological events related to the surgical anesthetic act. These include deterioration of the effector responses of the hypothalamus (tending to conserve heat), heat distribution between the central compartment and the periphery, and net heat loss to a generally colder environment, such as the surgical ward. Hypothermia is often an undetected complication of the anesthetic act due to the lack of regular temperature monitoring. It is not considered a basic standard of care, despite the fact that in recent years new guidelines and recommendations have emerged, which suggest its implementation in all patients in whom the duration of their surgery is expected to last longer than 1 hour. The measures aimed at keeping the patient normothermic can be classified as passive, within which the simplest is to cover the patient for as long as possible during their presence in the ward, and active, which are those that transfer heat to the body, within the which the most effective is the use of convective heat blankets. It has recently been suggested that prewarming the patient before inducing anesthesia is an efficient strategy to avoid hypothermia, decreasing temperature differences between core and peripheral tissues. However, the effectiveness of this measure remain to be evaluated with prospective, randomized trials. In the context of the emergency patient, although hypothermia shows the same characteristics as in the elective patient, it becomes more relevant in three clinical settings: patient with major burns, patient in hemorrhagic shock and the polytraumatized patient. In these scenarios, keeping the patient normothermic will prevent a series of serious complications, which can strongly affect mortality.
\end{abstract}

\section{RESUMEN}

La hipotermia perioperatoria es una complicación frecuente de la anestesia general, pero que también se puede presentar en pacientes sometidos a anestesia regional. Se relaciona con un aumento significativo de la morbilidad y mortalidad perioperatorias, donde se han identificado complicaciones como aumento de la incidencia de infección del sitio quirúrgico, retardo de la cicatrización, alteraciones de la coagulación, aumento del sangrado quirúrgico, de los eventos cardiacos perioperatorios, disminución del metabolismo de drogas implicadas en la anestesia y sensación de gran incomodidad del paciente en el posoperatorio inmediato, por

\footnotetext{
Hospital de Urgencia Asistencia Pública, Universidad de Santiago.
}

Fecha de recepción: 15 de noviembre de 2020

Fecha de aceptación: 17 de noviembre de 2020

\section{ORCID}

0000-0001-9243-0910

Correspondencia:

Renato Chacón Abba

rchacon@mi.cl 
la presencia de calosfríos. La disminución de la temperatura central del paciente se debe a un combinación de eventos fisiológicos relacionados con el acto anestésico quirúrgico, con deterioro de las respuestas efectoras del hipotálamo tendientes a conservar calor, fenómenos distributivos de calor entre el compartimiento central y la periferia del propio paciente y pérdida de calor neta hacia un medio ambiente en general más frío, como lo es el pabellón quirúrgico. El hecho de que la hipotermia sea muchas veces considerada una complicación no detectada del acto anestésico, se debe a que aún la monitorización regular de la temperatura no se considera un estándar básico de cuidado, pese a que en los últimos años han surgido nuevas guías y recomendaciones, que sugieren que ésta sea implementada en todo paciente en que se proyecte una duración de la cirugía mayor a 1 hora. Las medidas tendientes a mantener al paciente normotérmico, pueden ser clasificadas en pasivas, dentro de las cuales la más simple es cubrir al paciente el mayor tiempo posible durante su presencia en pabellón y activas, que son aquellas que transfieren calor al cuerpo, dentro de las cuales la más efectiva es el uso de mantas de calor convectivo. Recientemente, se ha sugerido que una de las estrategias eficientes para evitar la HPO es el precalentamiento del paciente, que permite que sus tejidos periféricos estén a mayor temperatura al momento de inducir la anestesia, sin embargo, la efectividad de esta medida debe ser evaluada con estudios prospectivos y aleatorizados más concluyentes. La hipotermia en el contexto del paciente de urgencia, si bien presenta las mismas características que en el paciente electivo, cobra mayor relevancia en tres escenarios clínicos: el gran quemado, el paciente en shock hemorrágico y el paciente politraumatizado, escenarios en que mantener al paciente normotérmico, implicará evitar una serie de complicaciones graves, que pueden incidir fuertemente en la mortalidad.

\section{Introducción}

a hipotermia perioperatoria (HPO), definida como una temperatura central inferior a $36^{\circ} \mathrm{C}$, es una -complicación que, si bien ha sido descrita extensamente en la literatura desde hace décadas, continúa siendo frecuente en la actualidad. Las series más conservadoras le otorgan una incidencia de al menos el $20 \%$ de los pacientes sometidos a anestesia general[1].

Esta complicación ha recibido también los nombres de "hipotermia perioperatoria accidental", concepto erróneo puesto que al tratarse de un fenómeno ampliamente conocido por los anestesistas no se le puede considerar un accidente e "hipotermia perioperatoria inadvertida", concepto que dice relación con que la medición de la temperatura corporal durante el acto anestésico, aún no es considerada un estándar dentro del monitoreo básico, ni por muchos especialistas ni por las guías clínicas de muchas sociedades científicas, lo cual la convierte en un fenómeno no detectado y desde luego no tratado en una amplio porcentaje de pacientes[2].

Existe evidencia científica de niveles altos, que demuestra que la HPO se relaciona con un aumento significativo de la morbilidad y de la mortalidad perioperatoria. Principalmente durante la década de los noventa, se publicó una serie de estudios que demostraron su correlación con aumento de la incidencia de infección del sitio quirúrgico y retraso de la cicatrización[3],[4], deterioro de la coagulación, aumento de las pérdidas sanguíneas y de la tasa de transfusión de hemoderivados[5]-[7], aumento de eventos cardiacos perioperatorios (isquemia miocárdica y taquicardia ventricular)[8], disminución del metabolismo de muchas drogas, entre ellas varias relacionadas con el acto anestésico con la consiguiente prolongación de la estadía en la sala de recuperación anestésica[9]-[12]. También se reportan complicaciones menores, pero igualmente importantes para el paciente como calosfríos, activación simpática y malestar en el período del despertar[13]-[15]. La gran mayoría de estos estudios mostró significancia estadística en la incidencia de complicaciones, cuando se comparó pacientes normotérmicos con pacientes hipotérmicos.

Este acúmulo de evidencia de hace más de dos décadas, significó que durante varios años no se publicaran estudios estandarizados, dado el conflicto ético que significaba dejar que la temperatura corporal del paciente bajara en forma intencionada durante la cirugía, cuando se pretendía comparar este grupo con un grupo control. No obstante, en los últimos años han sido publicados algunos estudios prospectivos, aleatorizados y metaanálisis que confirman la relación entre HPO, la magnitud del sangrado perioperatorio ${ }^{16}$ y la incidencia de muerte[17].

\section{Fisiología de la termorregulación}

Los mamíferos en su calidad de animales homeotermos y dentro de ellos el ser humano, mantienen su temperatura central prácticamente constante, en tan- 
to desviaciones significativas de ella pueden producir alteraciones de importantes procesos metabólicos. Para tal efecto, estos constan de un mecanismo de termorregulación eficiente, compuesto de receptores y vías aferentes que transmiten información hacia un centro termorregulador central, el que una vez procesada esta información activa respuestas efectoras tendientes a producir calor o disipar la pérdida calórica.

Existen receptores de frío y de calor distribuidos en el cuerpo, cuyas señales viajan a través de fibras A-delta y $C$ respectivamente; estas señales son procesadas a nivel de la médula espinal y otros sitios del sistema nervioso central para alcanzar finalmente el hipotálamo, que ejerce la función de "centro termorregulador"[18]. Las respuestas autonómicas que surgen desde el hipotálamo, derivan del procesamiento de la información proveniente de cinco orígenes: superficie de la piel, órganos torácicos y abdominales profundos, médula espinal, el propio hipotálamo y otras estructuras cerebrales, cada uno de ellos contribuyendo en forma bastante estricta con $20 \%$ de dicha información[19]. Por su parte, las respuestas conductuales del individuo vigil, derivan principalmente del procesamiento de información proveniente de receptores en la piel[20].

El hipotálamo tiene un doble sistema de regulación de la temperatura. Así, la porción anterior, compuesta por centros parasimpáticos, es la encargada de disipar el calor, mientras que la posterior, con centros simpáticos, conserva y mantiene la temperatura corporal. El umbral sobre el cual activa mecanismos de disipar el calor (umbral del calor) y bajo el cual activa mecanismos de conservación de temperatura y producción de calor (umbral del frío), se encuentran a tan sólo $0,2^{\circ} \mathrm{C}$ de distancia y en torno a una temperatura central de $37^{\circ} \mathrm{C}$, no obstante, el ciclo circadiano y el ciclo menstrual pueden producir modificaciones del orden de $1^{\circ} \mathrm{C}$ y $0,5^{\circ} \mathrm{C}$ respectivamente[21]. En consecuencia, en condiciones normales existe un estrecho "rango de temperatura central interumbral", por fuera del cual se activan las respuestas autonómicas, con el objetivo de mantener dicha temperatura dentro del rango establecido.

La respuesta termorreguladora más eficiente es el comportamiento del individuo, quien, ante situaciones de frío o calor, principalmente percibido a nivel de la piel, reacciona abrigándose, desabrigándose o acercándose a fuentes de calor o frío. Por supuesto, en el caso de un paciente sometido a anestesia general esta respuesta se encuentra abolida por la inconciencia, por lo cual el individuo queda a merced exclusiva de la activación de las respuestas autónomas.

Sin embargo, la HPO no es una complicación ex- clusiva de la anestesia general. En el caso de la anestesia regional (especialmente neuroaxial) la sensación de calor inicial que el paciente percibe en la zona bloqueada, puede conducirlo a una errónea interpretación de la temperatura ambiente, pero sorprendentemente también el sistema termorregulatorio reconoce la piel de las zonas bloqueadas como anormalmente alta[22], por lo cual estos pacientes también son susceptibles de sufrir de hipotermia durante y después de la anestesia.

Las respuestas autónomas de defensa contra el calor son la sudoración y la vasodilatación cutánea y las respuestas de defensa contra el frío son la vasoconstricción, la termogénesis sin calosfríos y los calosfríos. Cada una de estas reacciones presenta un nivel máximo de respuesta, de modo que, una vez superado el umbral y activada alguna respuesta, ésta se despliega con una determinada magnitud hasta alcanzar su expresión máxima, en tanto la temperatura detectada se desvía del rango normal.

De las tres respuestas autónomas tendientes a conservar o producir calor, la termogénesis sin calosfríos depende de la existencia de grasa parda propia de los lactantes pequeños[23]. Por lo tanto, los dos únicos mecanismos de conservación calórica disponibles en el paciente adulto son la vasoconstricción periférica que reduce las pérdidas calóricas a través de la superficie corporal, mecanismo mediado principalmente por receptores alfa1-adrenérgicos y que cierra shunts arteriovenosos periféricos de amplio diámetro $(100 \mu \mathrm{m})$, desviando el flujo sanguíneo hacia zonas centrales[24] y los calosfríos que a través de un mecanismo involuntario de contracción muscular producen calor, con el consiguiente aumento de la tasa metabólica y del consumo de oxígeno corporal hasta dos a tres veces su valor basal[25].

\section{Efectos de la anestesia sobre la termorregulación}

Como se señaló previamente, durante la anestesia general, el proceso de termorregulación del paciente descansa exclusivamente sobre las respuestas autónomas, teniendo en cuenta la incapacidad de éste de modificar su comportamiento en relación a la sensación de calor o frío. Sin embargo, estas respuestas también se encuentran alteradas bajo el efecto de una amplia gama de drogas de uso regular en anestesia general, que modifican el umbral de activación tanto para respuestas al calor como al frío. Esta alteración es dosis dependiente y en general es más importante para las reacciones de vasoconstricción y calosfríos (hasta 3 veces más) que para la sudoración. Es decir, los pacientes anestesiados son más vulnerables al frío 
que al calor[26]. Este efecto ha sido relacionado con el uso de opiáceos como el alfentanilo[27], hipnóticos como el propofol[28] y agentes inhalatorios como desfluorano e isofluorano[26],[29], presentándose además tanto en adultos[30] como en niños[31].

La elevación del umbral de respuesta al calor y descenso del umbral de respuesta al frío en el paciente anestesiado se traduce en una modificación del rango interumbral, que de $0,2{ }^{\circ} \mathrm{C}$ se amplifica a $4{ }^{\circ} \mathrm{C}$, es decir, se multiplica por veinte veces, determinando que las respuestas autónomas de preservación de la temperatura corporal no se activan hasta que el paciente alcanza una temperatura central cercana a los $35^{\circ} \mathrm{C}$. La amplia variedad de drogas inhalatorias y endovenosas que han sido relacionadas con el desplazamiento de los umbrales de activación de las respuestas autónomas y la amplificación del rango interumbral, da cuenta de que este fenómeno no está relacionado con un efecto farmacológico específico, sino con el simple hecho de anestesiar al paciente, por cualquier vía farmacológica. Es decir, un paciente anestesiado mantiene su hipotálamo "también anestesiado", al menos para los efectos de mantener un control estricto de la temperatura corporal.

Algunos estudios de este fenómeno no sólo demuestran modificación del umbral de activación de las respuestas autónomas, sino también alteración de la amplificación de esta respuesta, en la medida que la temperatura se aleja más del rango normal. Además, se han demostrado alteraciones más importantes en el despliegue de las respuestas conservadoras, que en el de las respuestas disipadoras de calor. Es así como estudios que utilizan anestésicos inhalatorios muestran preservación de la intensidad de la repuesta sudorípara y vasodilatadora en un sentido, pero franco deterioro de la respuesta vasoconstrictora en el otro[32].

El deterioro de la termorregulación durante la anestesia convierte transitoriamente a un sujeto normalmente homeotermo en poiquilotermo, es decir, en un sujeto cuya temperatura corporal se modifica de acuerdo a la temperatura ambiental. Esta condición, asociada a la exposición del paciente a un ambiente frío durante su permanencia en la sala de operaciones, determina que por lejos la alteración térmica perioperatoria más frecuente sea la hipotermia. En otras palabras, la HPO es el resultado de una situación a la cual concurren dos fenómenos: una marcada alteración de la termorregulación del paciente y su exposición a situaciones ambientales que se traducen en un desbalance calórico.

Bajo condiciones normales, existe un tono vasomotor que mantiene un gradiente de temperatura de entre $2^{\circ} \mathrm{C}$ y $4{ }^{\circ} \mathrm{C}$ entre los compartimientos central y periférico. La existencia de este tono vasomotor no sólo explica esta diferencia de temperatura, sino que constituye el propio mecanismo de defensa, que limita la circulación de sangre del compartimiento central por un compartimiento periférico más frío, retornando luego con menor temperatura. La disminución del umbral de vasoconstricción a niveles inferiores a la temperatura del paciente, ocasiona la apertura de shunts arteriovenosos, permitiendo redistribución de flujo sanguíneo y con ello redistribución de calor corporal desde el compartimiento central al periférico, resultando en una disminución de $1{ }^{\circ} \mathrm{C}$ a 1,5 ${ }^{\circ} \mathrm{C}$ en la temperatura central durante la primera hora de anestesia general[33]. En este período, la pérdida de calor al medio ambiente si bien existe, contribuye escasamente a la disminución de la temperatura. En una segunda etapa, la pérdida de calor hacia el medio ambiente sí se constituye en el fenómeno principal, simplemente debido a que esa pérdida excede la producción metabólica de calor corporal[34]. Durante este período, la temperatura central disminuye en forma lineal a una velocidad menor a la de la primera etapa.

La transferencia de calor desde el cuerpo hacia al ambiente se puede producir a través de cuatro fenómenos físicos y/o químicos: radiación, convección, conducción y evaporación, todos ellos a partir de las superficies expuestas y de la respiración. La superficie de la piel da cuenta de $90 \%$ de la pérdida de calor y los fenómenos de radiación y convección se constituyen en los principales mecanismos. Teniendo en cuenta la preponderancia de estos dos mecanismos, es evidente que la superficie de la piel que más contribuye a la pérdida de calor es aquella que se encuentra expuesta al ambiente, en comparación con la que se encuentra apoyada en alguna superficie o cubierta por ropa, mantas o campos quirúrgicos.

La duración de esta etapa de pérdida de calor dependerá de la velocidad con que baja la temperatura central del paciente $y$, en consecuencia, con la velocidad con que se alcanza el nuevo umbral de activación de la respuesta autónoma de vasoconstricción. Una vez alcanzado dicho umbral y activado el fenómeno de vasoconstricción, se inicia una tercera etapa en que la temperatura central cesa su disminución, debido a que se establece un nuevo equilibrio entre la producción metabólica de calor y su pérdida hacia el medio ambiente. Sin embargo, dado que este equilibrio se logra una vez alcanzado el nuevo umbral de activación de la respuesta autónoma y que esto suele ocurrir a niveles de temperatura central cercanos o inferiores a los $35^{\circ} \mathrm{C}$, cuando esto ocurre, el paciente ya exhibe un 
nivel de hipotermia tal, que se asocia a la gran mayoría de las complicaciones descritas previamente.

En resumen, la disminución de la temperatura central en condiciones de anestesia general presenta tres fases claramente diferenciadas que se muestran en la Figura 1: una primera fase con una pendiente de rápida disminución de la temperatura, relacionada con fenómenos distributivos de calor entre los compartimientos central y periférico, una segunda fase con una pendiente más lenta, relacionada con pérdida neta de calor entre el cuerpo y el medio ambiente y una tercera fase de equilibrio en que no se producen mayores disminuciones de la temperatura central, luego de activados los mecanismos de vasoconstricción[35].

\section{Consecuencias de la hipotermia perioperatoria}

Niveles moderados de hipotermia aumentan la incidencia de infección y producen un retraso de la cicatrización del sitio quirúrgico. La menor resistencia de la herida operatoria a la infección se explica por dos factores: 1) un deterioro de la función inmune, secundario a alteración de la función oxidativa de los neutrófilos y de la función fagocítica de los macrófagos; 2) una disminución del flujo sanguíneo cutáneo con la consiguiente disminución de la entrega de oxígeno a nivel tisular[35]. En paralelo, se ha documentado la relación entre hipotermia y alteración del metabolismo proteico[3] y disminución de la síntesis de colágeno[4], ambos fenómenos relacionados con retardo de la cicatrización. En concordancia con estos factores, existen publicaciones que reportan que la incidencia de infección del sitio quirúrgico se triplica y la estadía hospitalaria aumenta en $20 \%$ en pacientes sometidos a cirugía coloproctológica electiva[4], cuando éstos sufren HPO.

Niveles similares de hipotermia se han relacionado con deterioro de la función plaquetaria[5] y con disminución de la activación de la cascada de la coagulación[6], ambos hallazgos obtenidos de estudios in vitro. Sin embargo, estos resultados se correlacionan bien con estudios in vivo, en pacientes sometidos a artroplastia de cadera, en quienes la existencia de hipotermia se relacionó con un aumento significativo en los niveles de sangrado y necesidad de transfusión de hemoderivados[7].

En un estudio prospectivo realizado a una población de 300 pacientes de alto riesgo coronario, sometidos a cirugía torácica, abdominal y vascular, aquellos cuya temperatura central descendió en promedio 1,5 ${ }^{\circ} \mathrm{C}$, presentaron tres veces más morbilidad cardiaca que el grupo que se mantuvo normotérmico[8].

En otro ámbito, la disminución del metabolismo

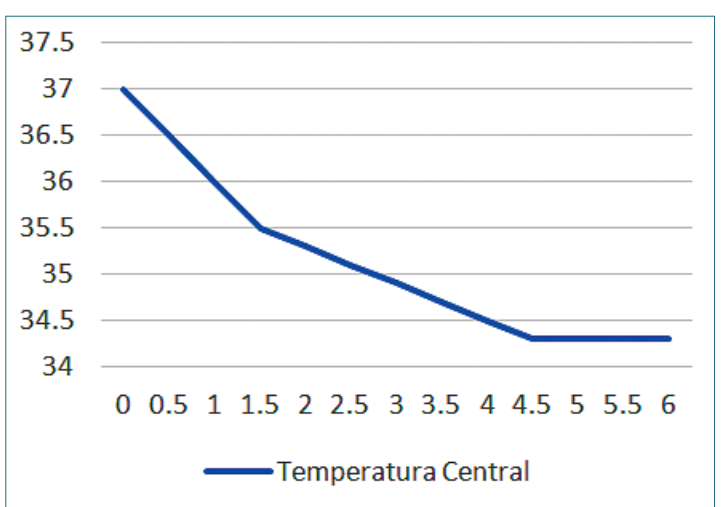

Figura 1. Pendientes de descenso de la temperatura central de un paciente sometido a anestesia general: se aprecia una primera etapa de descenso rápido durante la primera hora, en que la temperatura puede disminuir hasta $1,5^{\circ} \mathrm{C}$, producto de redistribución de calor entre el compartimiento central y el periférico; luego se aprecia una segunda etapa de descenso más lento, que es secundaria a pérdida de calor hacia el medio ambiente, por mecanismos de radiación, convección, conducción y evaporación; finalmente se aprecia una tercera etapa de plateau, en que el descenso de la temperatura tiende a detenerse, producto de la activación del mecanismo de vasoconstricción periférica.

de muchas drogas relacionadas con la anestesia, incluyendo hipnóticos, opiáceos, bloqueadores neuromusculares y anestésicos inhalatorios, se traduce en una significativa prolongación del período de permanencia en la sala de recuperación anestésica, aún cuando la obtención de un determinado nivel de temperatura corporal no se utilice como criterio de descarga[11].

Otras complicaciones como los calosfríos se presentan en hasta $40 \%$ de los pacientes en que no se han utilizado medidas de calentamiento intraoperatorio, cuando estos cursan su período de recuperación anestésica[13], respuesta asociada a activación adrenérgica[14] y a gran incomodidad[15]. Se pudiera especular que la activación adrenérgica descrita es la responsable del aumento de los eventos mórbidos cardiacos descritos previamente, pero dichos eventos cardiacos no guardan relación estricta con la ocurrencia de calosfríos, por lo que, sin excluir su influencia, no parecen ser el único factor relacionado.

De esta larga lista de complicaciones, una de las más estudiadas es el aumento de la incidencia de infección del sitio quirúrgico, debido a que, en la mayoría de los hospitales y países del mundo, este trazador constituye un indicador de calidad de prestación y un determinante de costos en salud. Distintas publicaciones que cifran su incidencia en $2 \%$ a $5 \%$ de todas las 


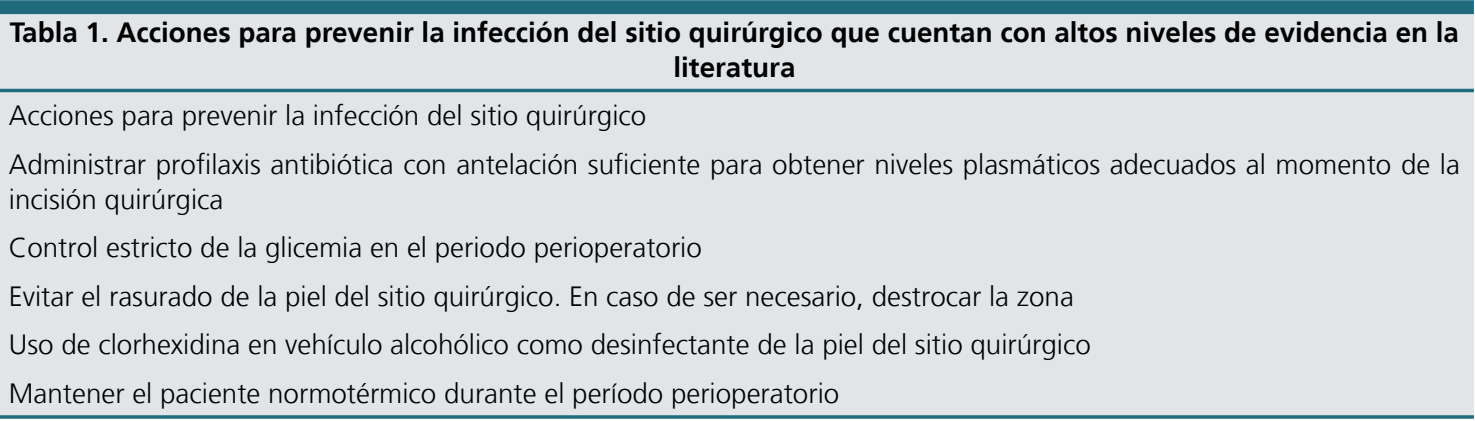

cirugías no ambulatorias, establecen que, en caso de presentarse, ésta se relaciona con un promedio de 7 a 11 días de prolongación de la hospitalización, con un aumento de 2 a 11 veces del riesgo de mortalidad y con un costo extra promedio de US\$20.785 por paciente[36[,[37]. Estas y otras cifras que tienen importancia clínica y administrativa, han motivado la realización de una serie de metaanálisis destinados a identificar las estrategias más eficientes para prevenir esta complicación. Estos estudios han coincidido en la identificación de cinco acciones que inciden en una disminución significativa de la tasa de infección de sitio quirúrgico, todos ellos con alto nivel de evidencia y fuertemente recomendados[38],[39]. Dentro de estas acciones, enumeradas en la Tabla 1, se incluye la mantención de la normotermia perioperatoria.

Atendiendo a estos estudios y su alto nivel de evidencia, el Ministerio de Salud de Chile publicó con fecha 05 de julio de 2017, la Resolución Exenta No 894, que "Aprueba la Norma General Técnica No 190 para la Prevención de Infección de Herida Operatoria", en cuyo artículo No 13 señala: "Se aplicarán medidas de prevención de hipotermia en los pacientes intervenidos en cirugías de más de una hora de duración" y luego establece: "En los pacientes en los cuales esté indicada la prevención de la hipotermia se llevará registro de la temperatura corporal del paciente durante la cirugía en los registros de seguimiento de variables intraoperatorias incorporados en los registros de anestesia u otros"[40]. Es decir, la norma obliga a monitorizar la temperatura y actuar en consecuencia en todo paciente en que se proyecte una cirugía de más de una hora de duración. Sin embargo, a más de dos años de publicada, esta norma no se encuentra aún socializada entre todos los anestesistas del país o no puede cumplirse por falta de insumos.

\section{Monitorización de la temperatura durante la anestesia}

Pese a la gran cantidad de información disponible en la literatura en relación a la fisiología de la termorregulación, a su alteración durante la anestesia, a la alta incidencia de la HPO y a la morbimortalidad relacionada con el fenómeno y teniendo en cuenta que el grueso de esta información científica surgió hace ya más de dos décadas, es llamativo que ésta se constituya aún en una de las complicaciones perioperatorias más frecuentes.

Es probable que al menos en parte, la causa de esta alta incidencia tenga relación con que hasta el día de hoy el monitoreo de la temperatura no se ha constituido como un estándar de cuidado del paciente anestesiado. En un estudio del año 2007 en que se evaluó vía encuesta a 316 hospitales de 17 países europeos, la tasa de monitoreo de la temperatura alcanzó apenas el 19,4\% de todos los pacientes anestesiados (25\% de los pacientes sometidos a anestesia general y $6 \%$ de los pacientes sometidos a anestesia regional)[41]. En un estudio colombiano similar publicado el año 2016, los encuestados refirieron monitorizar la temperatura siempre o casi siempre en tan sólo el $27 \%$ de los pacientes[42].

Las guías clínicas de estándares de monitoreo que publican las diferentes sociedades científicas a nivel local, regional y mundial, son a veces vagas y a veces contradictorias, respecto a la monitorización de la temperatura durante el acto anestésico.

Los Estándares de Monitoreo Anestésicos Básico de la ASA (American Society of Anesthesiologists, cuya última actualización data del año 2015 establecen lo siguiente: "Durante toda anestesia, la oxigenación, ventilación, circulación y temperatura del paciente deben ser continuamente evaluadas", afirmación que sugiere que el monitoreo de la temperatura, entre otros, constituye un estándar básico. No obstante, en un párrafo posterior se señala "cada paciente que reciba anestesia debe tener monitoreo de la temperatura, cuando cambios clínicos significativos en la temperatura corporal son proyectados, anticipados o sospechados", sin que se especifique qué se entiende por cambios clínicos significativos o 
el tiempo de anestesia en que se presume que dichos cambios podrían ocurrir[43].

Por su parte, los “Estándares Internacionales para la Práctica Segura de la Anestesia", documento elaborado por la World Health Organization y la World Federation of Societies of Anaesthesiologists, publicados el año 2018, establecen que "el monitoreo intermitente de la temperatura es RECOMENDADO", para luego señalar: "Un método de medición de la temperatura debe estar disponible y ser usado a intervalos frecuentes cuando está clínicamente indicado (ejemplo: anestesias prolongadas y complejas y niños menores). La disponibilidad y uso de métodos de medición de la temperatura continuos electrónicos en pacientes apropiados es SUGERIDA"[44]. Al respecto es necesario aclarar que los niveles RECOMENDADO y SUGERIDO de acuerdo a la misma guía clínica, deben ser practicados cuando la disponibilidad de recursos lo permite y cuando ello es apropiado para el prestador de salud local. De ello se infiere que la medición de temperatura no es para estas instituciones un estándar básico necesario en todo acto anestésico, sino un estándar sujeto a interpretaciones clínicas y presupuestarias. Sin embargo, el punto más discutible de este documento es que al referirse a lo "clínicamente indicado" se hace referencia a "anestesias prolongadas y complejas y niños menores", en circunstancias que la evidencia científica establece que la temperatura corporal puede descender hasta $1,5^{\circ} \mathrm{C}$ durante la primera hora y que este cambio no se encuentra limitado a anestesias complejas ni menos a niños menores.

Las Recomendaciones Clínicas de la Sociedad de Anestesiología de Chile sobre Disponibilidad y Uso de Monitorización Perioperatoria, documento actualizado el año 2017, establecen textualmente: "Este grupo de trabajo considera en consenso que la monitorización de la temperatura es un estándar mínimo de atención y un deber ético intrínseco a la práctica médica. Por ello, recomendamos fuertemente: el uso de termómetro para todo paciente que ingresa a procedimientos de más de 30 minutos de duración y que la medición central de la temperatura esté disponible para todo paciente" [45], lo que constituye un avance significativo en el tema en relación a otras sociedades de la especialidad.

El monitoreo directo de la temperatura central o la posibilidad de inferir ésta a partir de una medición más periférica, es un tema complejo considerando los múltiples sitios de medición, los múltiples mecanismos existentes, la gran variación de datos que puede verificarse en un mismo sitio dependiendo de diferentes factores y el nivel de invasividad que significa cada método. En general son considerados sitios de medición de temperatura central la arteria pulmonar, la membrana timpánica, el esófago distal y la nasofaringe. En la medida que estos sitios no se pueden usar, principalmente por motivos de invasividad, de dificultad de acceso o no disposición de la técnica, puede considerarse mediciones en sitios en que el valor que se obtendrá será "cercano a la temperatura central", pero siempre teniendo en cuenta que su exactitud es variable. Estos sitios son la boca, la axila, la vejiga, el recto y la superficie de la piel[46].

La Tabla 2 resume la mayoría de los métodos de medición de temperatura corporal disponibles y sus características en términos de precisión y latencia de la medición, confort para el paciente y aspectos relevantes, en relación a variabilidad y riesgo[47].

A pesar de que esta tabla se origina en un estudio publicado por Cork en 1983, sus datos son perfectamente aplicables el año 2020 y tienden a repetir un patrón: cuanto más exacto es el sistema de medición, más invasivo y/o incómodo para el paciente, lo cual impone un límite al uso de los sistemas más precisos en pacientes bajo anestesia regional y en pacientes que cursan sus períodos pre y postoperatorio. Una excepción a esta regla es la medición de la temperatura central mediante la tecnología de "canal de flujo cero de calor". Este sistema, que se muestra en la Figura 2, consta de un electrodo que se adhiere a la piel de la frente, cuya periferia posee un aislante térmico que impide la disipación de calor; posee un filamento central que produce calor, que se transmite hacia la piel ubicada inmediatamente en contacto al centro del electrodo. En la medida que el electrodo produce calor y la piel subyacente se vasodilata, se produce un canal de flujo de calor desde los tejidos subcutáneos hacia un sensor ubicado contiguo al filamento productor de calor. Cuando el flujo de calor a través de ese canal central se vuelve cero, el sensor lo interpreta como el equilibrio entre el calor subcutáneo y el calor producido por el electrodo y determina en ese nivel la temperatura central como se esquematiza en la Figura 3.

En el contexto de cirugía cardiaca, que suele producir bruscos cambios de temperatura en el paciente, sobre todo durante el período de circulación extracorpórea, se comparó las mediciones realizadas con el sistema de canal de flujo cero de calor (Spot On), con mediciones realizadas con catéter de arteria pulmonar, encontrándose una desviación promedio de la medición de $-0,23{ }^{\circ} \mathrm{C}$ durante el intraoperatorio y $-0,32{ }^{\circ} \mathrm{C}$ en el postoperatorio[48]. Estos resultados, coincidentes con otros estudios que utilizaron como gold standard el catéter de arteria pulmonar, demues- 


\begin{tabular}{|c|c|c|c|c|}
\hline \multicolumn{5}{|c|}{ Comparación de los diversos métodos de monitoreo de la temperatura } \\
\hline Sitio & Precisión & Latencia & Confort & Detalles \\
\hline Arteria Pulmonar & Excelente & Baja & Bajo & - Riesgo asociado a la punción venosa \\
\hline Esófago distal & Buena & Baja & Bajo & $\begin{array}{l}\text { - Riesgo de perforación esofágica } \\
\text { - Limitación en anestesia regional }\end{array}$ \\
\hline Nasofaringe & Buena & Baja & Bajo & $\begin{array}{l}\text { - Riesgo de desplazamiento } \\
\text { - Riesgo de laceración y epistaxis }\end{array}$ \\
\hline Vejiga & Buena & Baja & Bajo & $\begin{array}{l}\text { - Riesgo de infección urinaria } \\
\text { - La precisión de la medición varía con el nivel de } \\
\text { producción de orina }\end{array}$ \\
\hline Recto & Moderada & Alta & Bajo & $\begin{array}{l}\text { - Riesgo de perforación rectal } \\
\text { - La precisión de la medición varía con el nivel de } \\
\text { ocupación de la ampolla rectal }\end{array}$ \\
\hline $\begin{array}{l}\text { Membrana timpánica } \\
\text { (medición de contac- } \\
\text { to) }\end{array}$ & Buena & Baja & Bajo & $\begin{array}{l}\text { - Riesgo de perforación timpánica } \\
\text { - Riesgo de desplazamiento }\end{array}$ \\
\hline $\begin{array}{l}\text { Membrana timpánica } \\
\text { (medición infrarroja) }\end{array}$ & Baja & Baja & Alto & $\begin{array}{l}\text { - Errores e imprecisiones de la medición } \\
\text { - No es posible medición continua }\end{array}$ \\
\hline Mucosa oral & Moderada & Baja & Moderada & $\begin{array}{l}\text { - Errores e imprecisiones de la medición } \\
\text { - No es posible medición continua }\end{array}$ \\
\hline Axila & Baja & Alta & Alto & $\begin{array}{l}\text { - Errores e imprecisiones dependiendo del posi- } \\
\text { cionamiento del termómetro } \\
\text { - No es posible medición continua }\end{array}$ \\
\hline
\end{tabular}

tran una excelente relación entre ambas mediciones y abren la posibilidad de registrar temperaturas muy cercanas a la central, con un método cómodo y no invasivo, lo cual permite su uso en todo tipo de anestesias y a través de todo el período perioperatorio. La principal limitante al uso extendido de este tipo de monitoreo de temperatura es el costo del electrodo, por lo cual probablemente su incorporación comenzará por aquellos pacientes en que el control de la temperatura guarda mayor relación con mejores resultados clínicos.

\section{Intervenciones para mantener la temperatura central durante la anestesia}

Existen múltiples estrategias destinadas a intentar mantener normotérmico al paciente sometido a anestesia. Las intervenciones dirigidas a este objetivo se pueden dividir en dos grandes grupos: calentamiento pasivo y calentamiento activo.

Las maniobras de calentamiento pasivo son aquellas que persiguen limitar las pérdidas de calor principalmente por radiación y por convexción, de manera

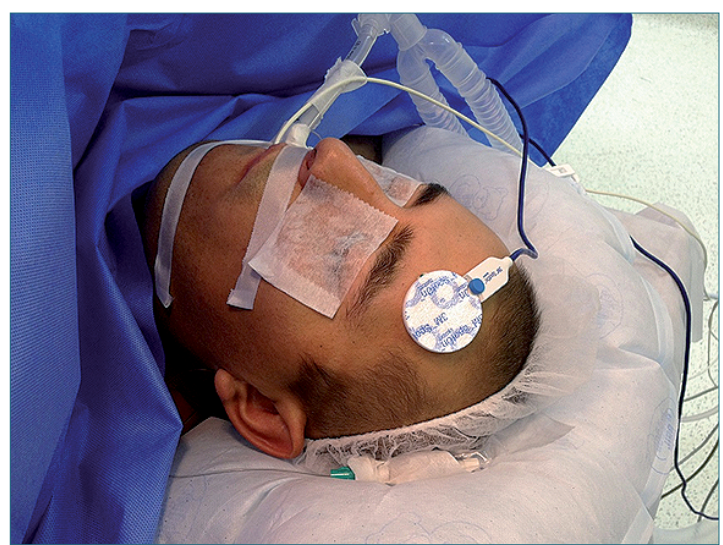

Figura 2. Electrodo del sistema de canal de flujo cero de calor, instalado en la frente de un paciente (el paciente tiene instalado un termómetro oroesofágico con el cual se está comparando la precisión de ambas mediciones).

que no aportan calor extra al paciente, sino que evitan que la producción de calor metabólica se disipe en pérdidas hacia el medio ambiente. Por el contrario, 


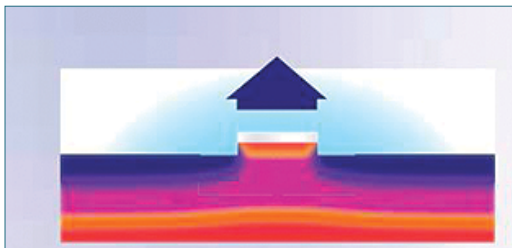

Abertura del canal

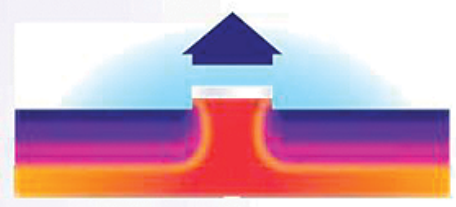

Canal en formación

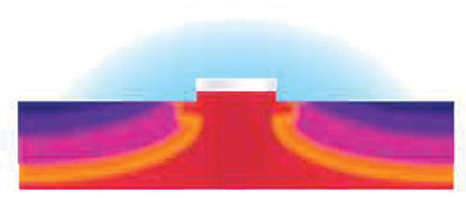

Canal finalizado

Figura 3. Esquema del funcionamiento de un electrodo de canal de flujo cero de calor: en la imagen de la izquierda el filamento central comienza a producir calor que se transmite a la piel subyacente; en la imagen central existe ya un canal constituido en que el flujo neto de calor es desde los tejidos subcutáneos hacia el electrodo; en la imagen de la derecha el flujo de calor a través del canal es cero puesto que se igualan los niveles de temperatura. Ese valor es interpretado como la temperatura central del paciente.

las maniobras de calentamiento activo no sólo evitan pérdidas de calor proveniente del metabolismo corporal, sino también aportan calor extra. La Tabla 3 enumera las principales maniobras de cada categoría

\section{Calentamiento pasivo}

\section{Aumento de la temperatura de pabellón quirúrgico}

Como se señaló previamente, los principales mecanismos de pérdida de calor al medio ambiente se producen por radiación y convección a través de la superficie de la piel, por la cual ocurre el 90\% del fenómeno, si bien a ella se pueden agregar otras superficies importantes, como es el interior de las cavidades corporales, cuando se realizan grandes incisiones quirúrgicas.

Elevar la temperatura del pabellón quirúrgico con el objetivo de minimizar las diferencias entre el cuerpo del paciente y el ambiente es una maniobra que disminuye la velocidad de pérdida de calor. Sin embargo, se trata de una maniobra controversial, principalmente por la incomodidad que esto genera en el equipo quirúrgico que, bajo las luces de pabellón, suele sentirse incómodo. Desde hace tiempo se sabe que para que esta maniobra sea efectiva se debe elevar la temperatura de pabellón al menos a $23^{\circ} \mathrm{C}$ [49], lo cual da cuenta de la limitación que presenta esta estrategia por dos motivos: 1) la temperatura central normal del paciente es de $37^{\circ} \mathrm{C}$ y la periférica es entre 2 y $4{ }^{\circ} \mathrm{C}$ inferior, por lo cual aún a esos niveles de temperatura ambiente existe una diferencia y una pérdida neta de calor que si bien será más lenta no se abolirá y 2) esa temperatura ambiental, con certeza, incomodará al equipo quirúrgico. En caso de niños lactantes y en particular en caso de recién nacidos y neonatos pe- queños, la temperatura de pabellón debería elevarse a niveles por sobre los $26^{\circ} \mathrm{C}$.

Además, se debe tener en cuenta que, como se señaló al describir los efectos de la anestesia sobre la termorregulación, las pérdidas de calor hacia el ambiente se relacionan con la segunda fase de descenso de la temperatura central, puesto que el primer grado y medio de descenso se explica por distribución de calor entre el compartimiento central y el periférico

\footnotetext{
Tabla 3. Métodos de calentamiento pasivo y activo: de estos métodos, las lámparas radiantes son de uso en cirugía de neonatos y el calentamiento de fluidos de irrigación y de $\mathrm{CO}_{2}$, son recursos utilizados en cirugías específicas

\section{Calentamiento pasivo}

- Aumento de la temperatura del pabellón quirúrgico

- Cobertores de las superficies expuestas

- Sábanas de tela

- Sábanas de papel

- Frazadas

- Mantas de algodón

- Mantas de aluminio

\section{Calentamiento activo}

- Lámparas radiantes (servocunas)

- Mantas eléctricas

- Colchones o mantas de circulación de agua

- Mantas de flujo de aire forzado (convectivo)

- Calentamiento de fluidos intravenosos

- Calentamiento de fluidos de irrigación

- Calentamiento y humidificación de gases anestésicos

- Calentamiento de $\mathrm{CO}_{2}$ para cirugía laparoscópica
} 
del propio paciente. Por lo tanto, si bien un ambiente de pabellón más cálido evitará que la periferia del paciente se enfríe más rápido y eso a su vez contribuirá a un menor intercambio de calor entre los compartimientos central y periférico, elevar la temperatura del recinto quirúrgico es principalmente útil en la segunda etapa de enfriamiento del paciente, que suele iniciarse cuando éste ya ha alcanzado temperaturas centrales inferiores a $36^{\circ} \mathrm{C}$.

\section{Cobertura de las superficies expuestas}

La conducta de cubrir al paciente mientras éste se encuentra en pabellón, no sólo tiene por objetivo su comodidad y el cuidado de su pudor, sino que constituye una primera maniobra simple y efectiva para enlentecer el descenso de su temperatura. Por cierto, la superficie quirúrgica deberá ser descubierta obligatoriamente durante la cirugía y tanto más amplia sea ésta, más superficie de piel quedará expuesta al ambiente.

Se debe tener en cuenta dos circunstancias que acelerarán la pérdida de calor por fenómenos convectivos en tanto el cuerpo del paciente esté descubierto: la primera es el proceso de preparado de la piel del campo quirúrgico que implica el lavado con soluciones jabonosas y el pincelado con antisépticos en vehículo alcohólico, productos que humedecen dicha superficie; la segunda, es el sistema de ventilación del pabellón quirúrgico a través de filtros bacterianos que, de acuerdo a muchas normas sanitarias, exigen un recambio del aire de la sala de al menos 15 veces por hora, lo cual implica un alto flujo aéreo por sobre la piel del paciente.

Tomando en cuenta esta situación, las medidas más apropiadas para minimizar este fenómeno incluyen: postergar lo más posible la exposición de la zona quirúrgica hasta el momento mismo en que se realizará la preparación de la piel, descubrir exclusivamente la zona quirúrgica manteniendo el resto del cuerpo cubierto y cubrir completamente al paciente tan pronto se hayan colocado los apósitos una vez concluida la cirugía.

Existen múltiples materiales del que pueden estar fabricados los diferentes tipos de cobertores a utilizar en pabellón, incluyendo simples sábanas de papel o tela, frazadas y mantas de algodón o aluminio; dependiendo del tipo de material éstas pueden ser de uso único o reutilizables, entibiadas o no y de costos muy disímiles. En virtud de estas diferencias es que podría surgir el cuestionamiento respecto a si mantas de materiales más sofisticados pudieran ser más efectivas en evitar pérdidas calóricas y en consecuencia justificar su mayor costo. Ya en 1991, Sessler publicó un estudio en que demostró que el simple acto de cubrir a un paciente disminuye las pérdidas calóricas en $30 \%$ y que no se observan diferencias clínicamente significativas entre las mantas confeccionadas con distintos materiales, por lo que en sus conclusiones señala que la cantidad de superficie corporal cubierta es más importante que la elección de un determinado material y una determinada región del cuerpo a cubrir[50].

El mismo autor posteriormente se cuestionó si agregar más cobertores produciría mayor conservación de calor por sobre ese $30 \%$ obtenido con una sábana o frazada y diseñó un nuevo estudio donde comparó el efecto de cubrir al paciente con una o tres mantas, diferenciando además para cada grupo el cobertor a temperatura ambiental o previamente precalentado. El estudio no demostró beneficios adicionales al agregar mayor cantidad de cobertores o al precalentar éstos[51].

\section{Calentamiento activo}

Dentro de los sistemas de calentamiento activo se encuentran los sistemas de servocunas neonatales, que transfieren calor por radiación y los sistemas de calentamiento de soluciones de irrigación y de $\mathrm{CO}_{2}$; los primeros en caso de lavados de cavidades y los segundos en casos de cirugía laparoscópica o videotoracoscópica. Por tratarse de técnicas para poblaciones y cirugías específicas, estos sistemas no serán tratados en detalle en este capítulo.

\section{Sistemas de calentamiento conductivo}

Dentro de esta modalidad de calentamiento activo se encuentran los colchones eléctricos y los colchones de agua circulante. En ambos casos el paciente se acuesta sobre una colchoneta que genera calor por un mecanismo diferente.

En el caso de la colchoneta eléctrica, ésta se encuentra conectada a una fuente de energía que genera un flujo de corriente continua que pasa por una resistencia, generando calor. Es capaz de generar temperaturas de entre $20^{\circ} \mathrm{C}$ y $40^{\circ} \mathrm{C}$, variable que es controlada por un termostato. Por supuesto el sistema debe tener aislamiento completo y satisfacer normas de seguridad eléctrica para su uso clínico. En el caso de la colchoneta de agua circulante, ésta posee una tubuladura en su espesor por la cual circula agua a una determinada temperatura, controlada por un termostato. 
Cualquiera de estas dos modalidades es más eficiente que un cobertor pasivo, puesto que la temperatura se mantiene constante, independiente del calor que sea transferido al cuerpo del paciente. Por el contrario, cualquier cobertor pasivo simplemente logrará un equilibrio intermedio entre su temperatura original y la del cuerpo del paciente, momento en el cual pierde todo efecto de transferencia de calor.

Estos dispositivos se utilizan debajo del cuerpo del paciente porque, dado su diseño, son estructuras más pesadas y menos flexibles, lo que dificulta su uso sobre el cuerpo. Esto establece un límite en su eficiencia como método de calentamiento, debido a que se contactan con sólo el $15 \%$ de la superficie corporal y justamente con la superficie de apoyo, que es la que pierde menos calor. Es por esta razón que los estudios que analizan la eficiencia de distintos métodos de calentamiento los ubican en un lugar intermedio por sobre los cobertores simples, pero por debajo de las mantas de circulación de aire forzado[52].

Otro problema potencial de estas colchonetas es que la generación de calor en su superficie se mantiene estable aún si el cuerpo del paciente se apoya más sobre determinada área, a diferencia de las mantas de aire forzado, que cesan el flujo de aire en las zonas en que el cuerpo la colapsa por apoyo. Esta condición pudiera generar un mayor riesgo de quemaduras en la piel de las zonas de máximo apoyo, no obstante, hasta la fecha existen solo casos reportados extraoficial y anecdóticamente, sin haber evidencia de alta calidad al respecto.

\section{Sistemas de calentamiento convectivo}

Las mantas de aire forzado son dispositivos de material liviano (semejante al papel) de doble hoja, que una vez insufladas por un compresor de aire a temperatura controlada, generan una serie de tubuladuras en su interior, por donde circula aire a una temperatura controlada por termostato. Sin embargo, no es la superficie de papel la que aporta calor al paciente, sino que es el propio aire el que sale del interior de la manta a través de múltiples orificios que se disponen en la cara que queda en directo contacto con el paciente. Por lo tanto, este dispositivo no genera intercambio de calor por contacto, sino por convección, ya que el aire tibio que se contacta con la piel del paciente circula en forma continua, renovándose permanentemente.

Además, de la mayor eficiencia de intercambio calórico que genera la convección por sobre el contacto, este dispositivo involucra un porcentaje mucho mayor de la superficie de la piel, debido a su uso tanto por sobre como por bajo el cuerpo y al efecto amplificador que ejerce la circulación de aire.

En concordancia con esta mayor eficiencia, los estudios que comparan el efecto del uso de mantas de aire forzado con colchonetas de circulación de agua han demostrado que en cirugías de corta duración (menor a las dos horas), ambos dispositivos muestran un efecto de conservación de la temperatura corporal similar, pero en la medida que las cirugías se prolongan, los sistemas convectivos se vuelven significativamente más efectivos[53].

Sin embargo, estos sistemas tampoco han estado exentos de cuestionamientos. El principal de ellos dice relación con la aprehensión de algunos cirujanos por la circulación de aire tibio cercano al sitio quirúrgico y su temor a que ello se traduzca en mayor tasa de infección. Respecto a este planteamiento, con fecha 30 de agosto de 2017 la FDA (Food and Drug Administration) publicó una carta titulada "Information about the Use of Forced Air Thermal Regulating SystemsLetter to Health Care Providers", en la que señala textualmente: "Después de una completa revisión de la información disponible, la FDA ha sido incapaz de identificar una asociación reportada consistente entre el uso de sistemas térmicos regulados de aire forzado e infección de sitio quirúrgico"[54].

\section{Calentamiento y humidificación de la vía aérea}

Existen dispositivos que se intercalan en el circuito de ventilación de la máquina de anestesia y que permiten el calentamiento controlado y la humidificación de la mezcla de gases frescos que se adicionan durante la ventilación mecánica. Sin embargo, menos del $10 \%$ del calor metabólico se pierde a través de la respiración, incluso cuando el paciente esta siendo ventilado con gas seco y frío. De este modo, esta maniobra influye en forma mínima en la temperatura central del paciente[55].

\section{Calentamiento de fluidos endovenosos}

La administración de un litro de cristaloides a temperatura ambiente o de una unidad de glóbulos rojos a $4{ }^{\circ} \mathrm{C}$ (que es la temperatura con la que suele ser enviada desde el banco de sangre) disminuyen la temperatura corporal central en aproximadamente 0,25 ${ }^{\circ} \mathrm{C}[56]$.

Del efecto señalado se desprende que, en la inmensa mayoría de los pacientes quirúrgicos, en que el aporte de fluidos endovenosos durante la cirugía no excede los 500 a 1.000 cc de cristaloides y no requieren de transfusión de hemoderivados, no se 
justifica el calentamiento regular de estas unidades, puesto que el efecto no será significativo. No obstante, existen recintos quirúrgicos en que por protocolo se entibian las soluciones cristaloideas en gabinetes calentadores de fluidos de temperatura controlada, lo cual no constituye una práctica errada puesto que se trata de equipamiento que no reporta mayores gastos ni uso de insumos desechables y se trata de una práctica que, finalmente, se aplica a todos los pacientes.

En contraposición, en aquellas cirugías en que el volumen infundido es mayor (algunos autores establecen el límite en forma subjetiva en dos litros), el calentamiento de fluidos minimiza las pérdidas de calor. En estos pacientes, se pueden utilizar los gabinetes de calentamiento previamente descritos que permitirán entibiar todas las unidades de cristaloides que recibirá el paciente (relevante cuando el paciente está recibiendo fluidos a través de múltiples vías venosas) o calentadores de fluidos de pasada, que son dispositivos que se intercalan en la bajada de suero a través de un set desechable, en el que la solución circula por un medio externo (seco o hídrico) que le transfiere calor, de manera que al abandonar el dispositivo en dirección a la vía venosa, ha adquirido una mayor temperatura. Como el equipo calentará los fluidos de un solo acceso, se deberán usar tantos dispositivos como accesos o se deberá privilegiar su uso en aquella vía en que el aporte de volumen es mayor.

En cualquier caso, no es posible transferir calor a los pacientes calentando los fluidos administrados[35],[52], puesto que las temperaturas a la cual éstos pueden ser infundidos es de $33^{\circ} \mathrm{C}$ a $41{ }^{\circ} \mathrm{C}$, por lo que el calentamiento de fluidos sólo evita que a la pérdida de calor cutánea se agregue el efecto de las soluciones frías. Por lo tanto, este método no constituye un sustituto del calentamiento cutáneo. La Figura 4 muestra el cambio de temperatura central media luego de infundidos distintos volúmenes de fluidos a distintas temperaturas. En él se observa que la infusión de fluidos a temperatura de $38{ }^{\circ} \mathrm{C}$, solamente evitará disminuir la temperatura central, sin lograr transferencia de calor hacia el paciente. En contraposición, se puede verificar el gran impacto que tiene transfundir fluidos a $4{ }^{\circ} \mathrm{C}$, que rápidamente disminuyen la temperatura central del paciente.

La Figura 5 describe la eficiencia de distintos métodos de mantención de la temperatura corporal. Se observa que mientras una manta de aire forzado puede elevar la temperatura corporal en hasta $4{ }^{\circ} \mathrm{C}$ en el lapso de 2 horas, el calentamiento y humidificación del aire de la vía aérea no logra el mismo objetivo al cabo de 8 horas.

\section{Precalentamiento}

Teniendo en cuenta que la caída inicial de la temperatura central de al menos $1,5^{\circ} \mathrm{C}$ durante la primera hora, se debe a redistribución de calor entre el compartimiento central y periférico del propio paciente, hay quienes han planteado que la primera medida tendiente a prevenir el descenso de la temperatura no debe ser el calentamiento del medio ambiente quirúrgico, sino el calentamiento del compartimiento periférico del propio paciente previo a la inducción anestésica. De esta manera, cuando se realice dicha inducción, momento en el cual el hipotálamo dejará de cumplir su estricto rol termorregulador y existirá vasodilatación periférica, ambos fenómenos encontrarán un compartimiento periférico más tibio y la sangre que circule por él retornará al compartimiento central sin haber sufrido una pérdida de calor relevante.

A partir de esta teoría, se plantea el concepto de "precalentamiento", acción en la cual durante un período de tiempo variable (habitualmente entre 15 y 40 minutos) previo a la inducción de la anestesia, se cubre al paciente con una manta de aire forzado programado a una temperatura de entre 40 y $43^{\circ} \mathrm{C}$ (la mayor temperatura que permiten los dispositivos), con el objetivo de calentar su compartimiento periférico[57]. Esta estrategia también ha sido utilizada en pacientes bajo anestesia regional[58].

Evidentemente, no es lo mismo planificar un precalentamiento de 15 minutos, acción que se puede realizar en el pabellón quirúrgico a partir del momento mismo en que el paciente ingresa, a prolongarlo a 40 minutos, caso en el cual, para no postergar la tabla quirúrgica, se debe iniciar desde su pieza o desde que el paciente ingresa a la sala de preanestesia (en caso de existir ésta). Por lo tanto, esta estrategia clínica implica un desafío organizativo mayor, sobre todo cuando se trata de una práctica que se realizará a todos los pacientes con riesgo de HPO. En relación a la dificultad de implementar precalentamientos prolongados, se han publicado algunos estudios donde se ha realizado este procedimiento por períodos de sólo 15 minutos, mostrando buenos resultados cuando se comparan con el uso de simples cobertores[59]. En el mismo sentido, existen publicaciones recientes que han incorporado un nuevo término: "el cocalentamiento", en que el calentamiento convectivo se inicia en forma simultánea con la inducción anestésica y no previamente[59]. Todos estos estudios muestran series pequeñas de casos, por lo que son necesarios más estudios bien diseñados y con un mayor núme- 

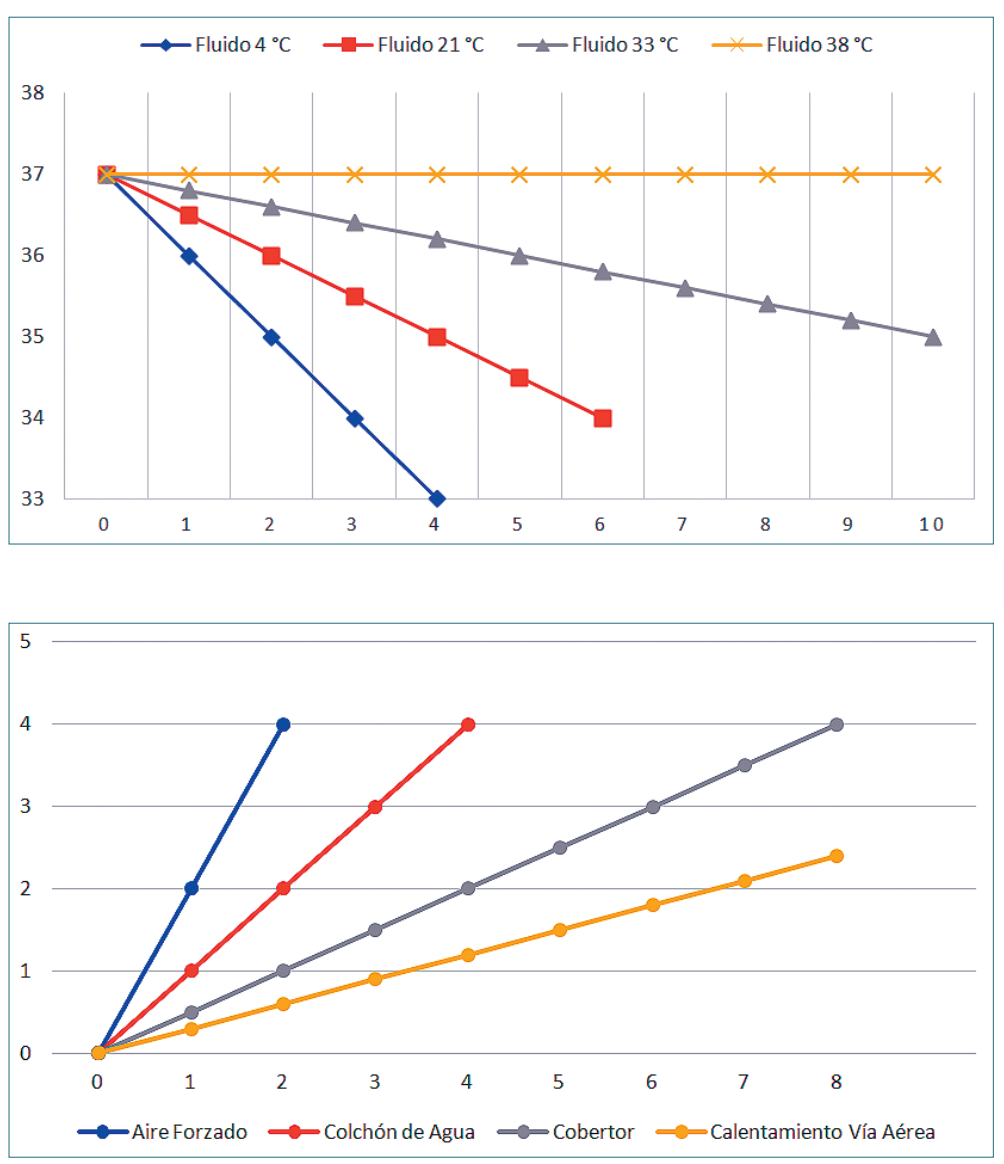

Figura 4. Cambio en la temperatura corporal media en relación a la infusión de distintos volúmenes de cristaloides o sangre (expresado en litros) a diferentes temperaturas. Se observa como 1 litro de fluidos a $4{ }^{\circ} \mathrm{C}$ puede bajar la temperatura central en $1{ }^{\circ} \mathrm{C}$ en tan sólo 1 hora, en tanto 10 litros de fluidos a 38 ${ }^{\circ} \mathrm{C}$ no modifican la temperatura central.

Figura 5. Diferencia en la efectividad para subir la temperatura corporal de cuatro maniobras (mantas de aire forzado, colchón de circulación de agua, cobertor simple y calentamiento y humidificación del aire de la vía aérea). Se muestra como mientras las mantas de aire forzado pueden elevar la temperatura en $4{ }^{\circ} \mathrm{C}$ en un lapso de 2 horas, el calentamiento y humidificación del aire de la vía area luego de 8 horas aún no logra ese objetivo[35],[52]. ro de pacientes, para establecer en forma definitiva cuánto es el tiempo necesario de precalentamiento que permita minimizar la tasa de HPO, con estrategias razonables que no alteren la ejecución de la tabla quirúrgica.

Andrzejowzki et al., compararon pacientes sometidos a cirugía de columna manejados en forma convencional (calentamiento convectivo intraoperatorio), con pacientes precalentados por 60 minutos a $38^{\circ} \mathrm{C}$ seguido luego con el mismo manejo convencional, analizando la evolución de la temperatura central durante toda la cirugía y evaluando la incidencia de HPO definida como una temperatura inferior a $36^{\circ} \mathrm{C}[60]$. La Figura 6 muestra la evolución de la temperatura a lo largo de la cirugía. En ella se confirma que ambos grupos disminuyen su temperatura central durante los primeros 40 minutos, para luego iniciar un lento proceso de recuperación que alcanza su máximo hacia el final de la cirugía. El segundo dato evidente es que el grupo precalentado disminuye menos su temperatura que el grupo control, diferencia que alcanza significancia estadística en las mediciones entre los 20 y 80 minutos. El tercer dato interesante es que, mientras más dura la cirugía, más normotérmicos están los pacientes al finalizar ésta.

En la Figura 6, sin embargo, no es evidente cuantos pacientes alcanzaron la hipotermia, definida como una temperatura inferior a $36^{\circ} \mathrm{C}$. La Figura 7 , muestra el porcentaje de pacientes de cada grupo que alcanzan niveles de temperatura definidos como hipotermia y se observa que los pacientes del grupo precalentado logran mantenerse normotérmicos en mayor proporción en cada uno de los tiempos registrados. En forma global, el $68 \%$ de los pacientes precalentados y sólo el $43 \%$ de los del grupo no precalentado, lograron mantenerse normotérmicos a lo largo de toda la cirugía $(P<0,05)$.

\section{El dilema de qué se entiende por HPO}

A partir del estudio anterior, donde se muestra la evolución continua de la temperatura central media 
de los pacientes, se puede plantear una interesante discusión respecto a cuál o cuáles de estas mediciones tienen impacto en la tasa de morbimortalidad. Existe un gran número de estudios que relacionan la temperatura final de la cirugía o la temperatura de arribo a la sala de recuperación anestésica con la incidencia de complicaciones, no obstante, Andrzejowzki muestra que pacientes que efectivamente presentaron HPO durante el procedimiento, se encuentran normotérmicos al abandonar el pabellón quirúrgico, por lo cual la medición final pierde valor.

En este escenario, es esperable que complicaciones como los calosfríos no se presenten al despertar del paciente dado que su temperatura central es normal, pero otras complicaciones como la tasa de infección del sitio quirúrgico pudieran relacionarse con la evolución de la temperatura a lo largo de toda la cirugía. Si este análisis es correcto, entonces para efectos de dicha complicación pudieran importar dos variables: la profundidad del nivel de hipotermia (cuál fue el nivel mínimo de temperatura central observada) y la duración del fenómeno (cuanto tiempo el paciente se mantuvo bajo los $36^{\circ} \mathrm{C}$ ).

Este nuevo concepto en que la temperatura se analiza como una variable evolutiva a lo largo del acto quirúrgico, relacionando dicha evolución con la incidencia de complicaciones, fue estudiado por Sun et al. en forma restrospectiva en 58.814 pacientes sometidos a cirugías no cardiacas de más de una hora de duración, todos manejados con dispositivos de aire forzado durante el intraoperatorio, evaluando las modificaciones de la temperatura esofágica a lo largo del procedimiento[61]. El primer hallazgo del estudio confirma un hecho ya descrito por Andrzejowzki: el hecho que en la totalidad de los pacientes la temperatura central disminuye durante la primera hora, para, posteriormente, recuperarse. Luego, el estudio establece umbrales de disminución de la temperatura en $36{ }^{\circ} \mathrm{C}, 35,5{ }^{\circ} \mathrm{C}, 35^{\circ} \mathrm{C}$ y $34,5^{\circ} \mathrm{C}$, registrando el porcentaje de pacientes que alcanzaron dichos umbrales y por cuánto tiempo se mantuvieron por debajo de él. La Figura 8 resume el comportamiento de los pacientes-en relación con dos variables: distintos umbrales de hipotermia y porcentaje de pacientes que se mantuvieron por debajo de uno de esos umbrales por determinado lapso. Se observa, por ejemplo, que el porcentaje de pacientes cuya temperatura disminuyó por debajo del umbral de $36^{\circ} \mathrm{C}$ es alto, pero respecto a la duración de esta condición, el $70 \%$ de ellos mantuvo temperaturas bajo ese umbral por un lapso superior a los 15 minutos, pero solamente un $4 \%$ la mantuvo por más de 240 minutos. Del mismo modo, cerca del $10 \%$ de los pacientes presentó temperatura inferior a $35^{\circ} \mathrm{C}$, pero sólo un pequeño porcentaje de ellos (5\%) mantuvo dicho nivel de hipotermia por más de 60 minutos.

De este modo, este estudio agrega una nueva forma de determinar el nivel de HPO: la integral del área bajo la curva de todo el período en que un paciente ha presentado una temperatura central inferior a 37 ${ }^{\circ} \mathrm{C}$, área a cuya magnitud concurre la profundidad en grados de la hipotermia por bajo el umbral en cada momento y el tiempo total en que permanece en dicha condición. El cálculo de dicha integral determina un número que cuanto mayor es, significa que el paciente presentó hipotermia más profunda, que permaneció más tiempo en dicha condición o ambas. Luego el estudio relaciona dicho número con el índice de probabilidad (OR) de que el paciente deba ser transfundido con glóbulos rojos durante el período intraoperatorio, demostrando una relación directamente proporcional entre la integral de hipotermia calculada y la tasa transfusional: si la integral calculada fue de 0,5 el OR se elevó a 1,10; si la integral calculada fue 16 el OR se elevó a 2,02

De este modo se utiliza una fórmula diferente de cálculo de la magnitud de la HPO y de su riesgo aparejado, lo cual se vuelve muy interesante en una

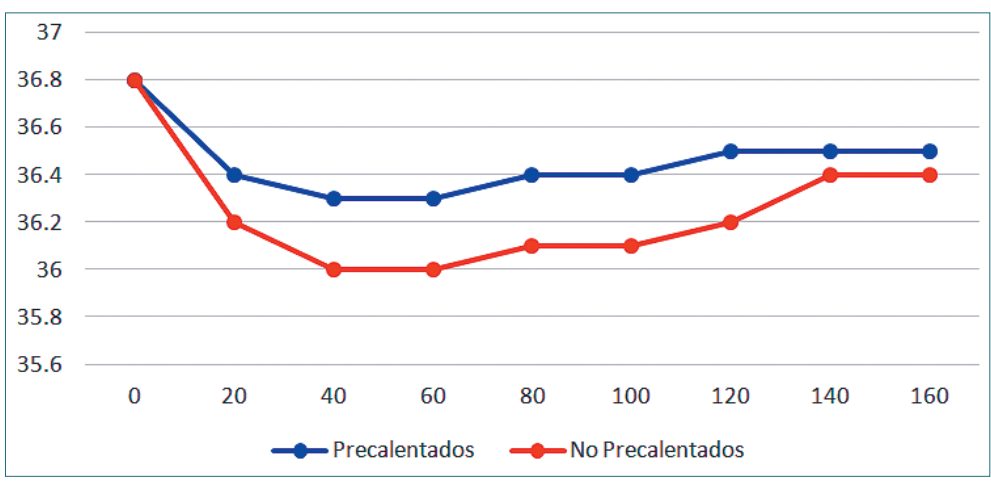

Figura 6. Evolución de la temperatura central media en pacientes sometidos a anestesia general para cirugía de columna, en grupos precalentados y no precalentados. Las diferencias de temperatura alcanzan significancia estadística a los 20, 40, 60 y 80 minutos[60]. 


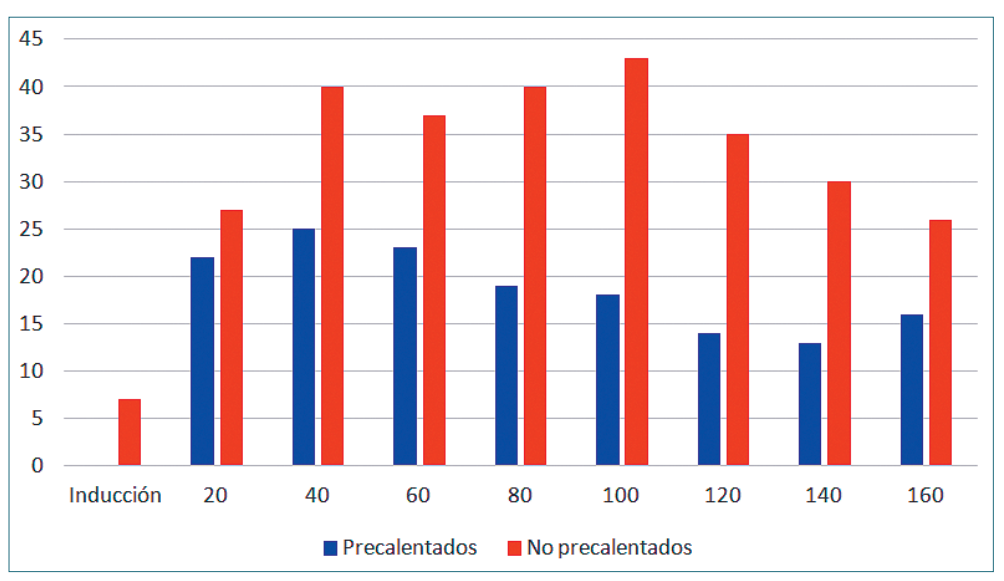

Figura 7. Porcentaje de pacientes que alcanzan una temperatura central bajo $36{ }^{\circ} \mathrm{C}$ (hipotermia) en cada tiempo de registro a lo largo de la cirugía[60]. población de pacientes que consistentemente tendió a la normotermia al finalizar la cirugía, por lo que la simple determinación de esta temperatura no hubiera sido útil.

\section{La HPO en el contexto del paciente de urgencia}

La incidencia, consecuencias, indicación de monitoreo y manejo de la HPO en el contexto de la mayoría de los pacientes de urgencia, son similares a aquellas de los pacientes sometidos a cirugías y procedimientos electivos. La excepción a ello la constituyen tres escenarios clínicos: el del paciente gran quemado, el del paciente en shock hemorrágico de causa no traumática y el del paciente politraumatizado.

La distinción entre el shock hemorrágico traumático y no traumático es necesaria, pues, si bien el paciente politraumatizado suele presentarse en shock hemorrágico, su cuadro habitualmente se acompaña de otras características clínicas, que pueden no presentarse en el caso de pacientes en shock hemorrágico de otro origen (ruptura de aneurisma aórtico, hemorragia digestiva, ruptura de embarazo ectópico, etc.) y que tienen implicancia en la relación riesgobeneficio de la hipotermia moderada.

\section{Gran quemado}

El paciente gran quemado se encuentra en alto riesgo de presentar hipotermia, tanto en la etapa inicial de resucitación, como durante las múltiples cirugías a las que habitualmente será sometido, con el objetivo de remover las zonas de piel dañadas en forma profunda, de asear y revisar el estado de las zonas receptoras y finalmente de cubrir dichas zonas

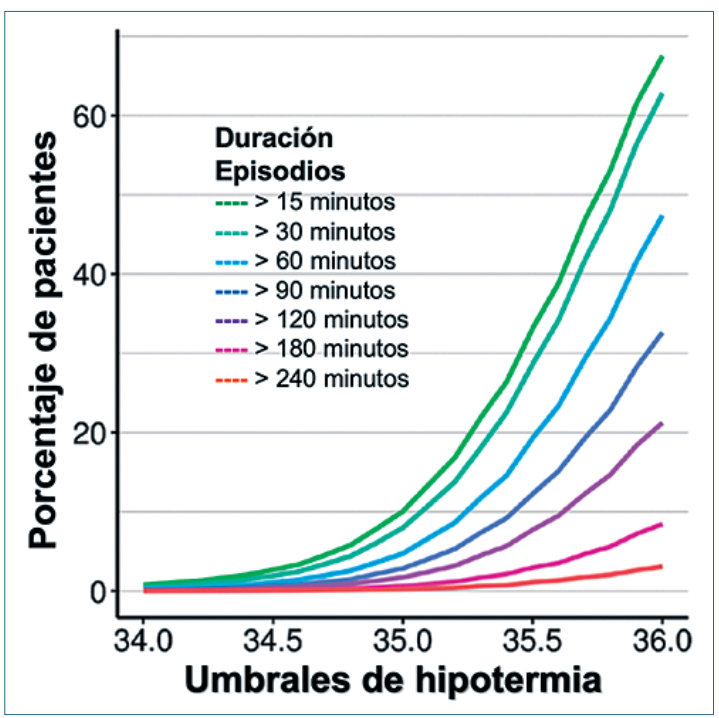

Figura 8. Porcentaje de pacientes que presentaron determinados umbrales de hipotermia, relacionado con el tiempo que se mantuvieron por debajo de ese umbral[61].

con injertos de piel sana.

La primera causa por la cual estos pacientes se encuentran en mayor riesgo de desarrollar hipotermia es la pérdida del efecto termorregulador protector que ejerce la piel sana. A ello se agrega que la respuesta inflamatoria sistémica secundaria a extensas superficies corporales quemadas influye en que el hipotálamo establezca como normal una temperatura central más alta que la temperatura habitual, lo que deriva en una tasa metabólica elevada, para mantener dicho aumento del umbral de temperatura. En consecuencia, la hipotermia es mal tolerada por estos pacientes, 
debido a que conduce a un exagerado aumento del consumo de oxígeno y una exacerbación de la respuesta catabólica a la injuria[62]. A las causas fisiopatológicas que contribuyen a generar hipotermia en el paciente gran quemado, se suman circunstancias del manejo clínico, tanto de la fase de resucitación como quirúrgica, que pueden agravar el cuadro.

En la fase de resucitación, el paciente gran quemado cursa inicialmente con un patrón hemodinámico de disminución profunda del débito cardiaco y aumento de las resistencias vasculares sistémica y pulmonar, secundario a una severa extravasación de fluidos hacia los tejidos quemados y sanos. De este modo, el volumen circulante efectivo disminuye dramáticamente, por transferencia de fluidos hacia la zona quemada que se inflama y hacia el resto de los tejidos no quemados que se edematizan[63]. Las maniobras de resucitación de esta primera etapa hemodinámica consideran obligatoriamente la reposición de volumen en grandes cantidades, que reemplacen los fluidos que están siendo extravasados hacia el intersticio. Si esta reposición de volumen no se realiza en forma entusiasta, el paciente cae en hipoperfusión tisular, perpetúa el shock y desarrolla falla multiorgánica, no alcanzando la segunda etapa hiperdinámica que se verifica a partir del tercer día de ocurrido el trauma.

Si bien la reposición de volumen debe titularse por objetivos fisiológicos y hemodinámicos, existen fórmulas ampliamente conocidas que guían su implementación, de las cuales las más conocidas son las fórmulas de Parkland y de Brookes[64], que utilizan solución ringer lactato (SRL) solo o mezclado con coloides y que para determinar el volumen total a infundir consideran el peso y la superficie total quemada del paciente. Como ejemplo, para que se pondere cuán importante es el aporte de volumen, de acuerdo a estas fórmulas, un paciente de $70 \mathrm{~kg}$ de peso que presenta una superficie corporal quemada de un $60 \%$ deberá recibir en las primeras 24 horas de resucitación $16.800 \mathrm{ml}$ de SRL de acuerdo a la fórmula de Parkland o $6.300 \mathrm{ml}$ de SRL y $2.000 \mathrm{ml}$ de coloides de acuerdo a la fórmula de Brookes.

Es evidente que, si estos rangos de volumen son infundidos a temperatura ambiental, sumado a las profundas alteraciones de termorregulación que presenta el paciente quemado, éste caerá en hipotermia rápidamente, con todas las consecuencias que ello implica, por lo cual es obligatorio el calentamiento de fluidos a infundir.

En estos pacientes el riesgo de hipotermia severa también aumenta exponencialmente durante las cirugías a las que son sometidos, sobre todo cuando las quemaduras son extensas y, por lo tanto, las superficies quirúrgicas expuestas son amplias[65]. En tal condición, la preocupación del equipo anestésico-quirúrgico por conservar la temperatura del paciente debe comenzar en el mismo momento en que éste ingresa. De este modo, los pabellones quirúrgicos deben ser mantenidos a temperaturas no inferiores a $26^{\circ} \mathrm{C}$ y conjuntamente, debe utilizarse colchonetas de agua circulante o mantas de aire forzado (habitualmente por debajo del cuerpo), para que el calentamiento convectivo involucre la mayor cantidad de superficie corporal posible.

\section{Shock hemorrágico y transfusión masiva}

El shock hemorrágico, particularmente cuando éste deriva en una transfusión masiva, suele acompañarse de coagulopatía, condición que dificulta el tratamiento definitivo del cuadro inicial de sangrado. Esta coagulopatía puede ser secundaria a una serie de factores que contribuyen en su etiología, dentro de los cuales se incluye: hemodilución de factores de coagulación (más relevante con el uso de hemoderivados fraccionados), plaquetopenia, disfunción plaquetaria, hiperfibrinólisis, hipotermia y, eventualmente, coagulación intravascular diseminada[66].

La mantención de la normotermia es una de las estrategias efectivas y primordiales en el manejo de pacientes con cuadros hemorrágicos severos y transfusión masiva, debido a la gran influencia que ésta tiene sobre casi todas las demás variables que derivan en una coagulopatía: enlentece la actividad de los factores de la cascada de la coagulación, reduce la síntesis de factores de la coagulación, puede producir hiperfibrinólisis, trombocitopenia y disfunción plaquetaria.

Estas alteraciones han sido observadas en estudios en animales[67],[68],[69] y corroboradas en humanos en estudios que, entre otros hallazgos, han demostrado que la hipotermia se relaciona con una reducción significativa de los niveles de tromboxano B2, que es un indicador de activación plaquetaria[70] y que dicha disfunción podría estar relacionada con alteración del funcionamiento de receptores glicoproteicos involucrados en la agregación plaquetaria[71]. Pero lo más importante es que éstas y otras observaciones tienen consecuencias significativas en el resultado clínico, donde pacientes hipotérmicos moderados $\left(35^{\circ} \mathrm{C} \pm\right.$ $0,5^{\circ} \mathrm{C}$ ) presentan mayor sangrado y requieren de más transfusiones de hemoderivados[7].

La principal causa de mortalidad de pacientes en shock hemorrágico que son transfundidos masivamente es la imposibilidad de lograr una adecuada hemostasia y en consecuencia la perpetuación del sangrado. Este sangrado sostenido puede tener ori- 
gen quirúrgico o estar influido por algún nivel de coagulopatía, cuyas causas pueden ser múltiples, dentro de las cuales la existencia de hipotermia moderada a severa es de gran relevancia. En consecuencia, prevenir la hipotermia constituye un eje central del plan terapéutico, que contribuirá a disminuir la mortalidad.

Considerando que, como se señaló previamente, 1 litro de cristaloides a temperatura ambiental o 1 unidad de glóbulos rojos a $4^{\circ} \mathrm{C}$, bajan la temperatura central del paciente en $0,25^{\circ} \mathrm{C}$, un evento de transfusión masiva, donde serán infundidos muchos litros de volumen, constituye el más característico de los escenarios donde la infusión de fluidos adquiere un rol preponderante en la alteración de la temperatura del paciente. En tal condición, la infusión de soluciones tibias (tanto cristaloides como hemoderivados) desde el principio del tratamiento, es vital para evitar un descenso significativo de la temperatura del paciente.

No obstante, se debe recordar que infundir fluidos a temperaturas de $38{ }^{\circ} \mathrm{C}$ a $40^{\circ} \mathrm{C}$, no transfiere calor extra al paciente y sólo se traduce en que el aporte de volumen no incide en enfriarlo más[35],[52]. En este escenario los otros mecanismos de pérdida de calor corporal siguen activos y deben ser manejados con los mejores recursos disponibles. En otras palabras, si bien el calentamiento de fluidos se encuentra plenamente justificado, sea a través de gabinetes de calentamiento de sueros o a través de calentadores de pasada, estos pacientes deben ser calentados en paralelo a través de mantas de aire forzado dispuestas de manera de cubrir la mayor superficie corporal posible, en virtud de la cirugía o procedimiento que se realiza.

\section{Paciente politraumatizado}

El trauma es la principal causa de muerte en individuos jóvenes (menores de 40 años), escenario donde el principal factor que produce mortalidad es la hemorragia incontrolable. En concordancia con ello, diferentes estudios han comprobado que la coagulopatía que se relaciona con el trauma juega un rol mayor en la incidencia de morbilidad y mortalidad en pacientes politraumatizados[72]. Esto tiene gran importancia clínica teniendo en cuenta que aproximadamente el $25 \%$ de los pacientes que sufren trauma severo, ingresan al servicio de urgencia con una coagulopatía aguda relacionada al trauma en curso[73].

La coagulopatía secundaria a trauma es multifactorial, pudiendo distinguirse al menos seis factores clínicos que solos o en conjunto, pueden dar inicio y acentuar al cuadro: injuria tisular, shock e hipoperfusión, hemodilución, hipotermia, acidosis e inflama- ción[74].

En consecuencia, la hipotermia relacionada con el trauma es un factor bien reconocido de morbilidad y mortalidad, principalmente relacionado con coagulopatía y a través de ésta, con la principal causa de muerte, que es el sangrado incoercible. En un estudio prehospitalario realizado en 302 pacientes politraumatizados, Helm et al.[75], encontraron que casi la mitad de ellos se presentaron hipotérmicos a su arribo al servicio de urgencia y que no hubo relación entre la estación del año y la frecuencia de hipotermia. Sin embargo, sí influyó en su incidencia que el paciente fuera mayor a 65 años y que hubiera tenido que ser extricado de un vehículo, es decir, factores que tienen que ver con la vulnerabilidad del paciente y con períodos de rescate en la vía pública más prolongados.

La Tabla 4 enumera las principales causas de hipotermia en el paciente politraumatizado, diferenciando aquellas que disminuyen la producción de calor o alteran la termorregulación y aquellas que aumentan las pérdidas de calor. Además, se pueden identificar causas propias del paciente y de las características del trauma y otras que se relacionan con su manejo clínico, que es sobre las cuales podemos intervenir principalmente. El trauma per se, sobre todo cuando se acompaña de sangrado importante e hipoperfusión tisular resulta en hipotermia por alteración de la termorregulación, pero principalmente porque para generar calor los tejidos requieren mantener el metabolismo aeróbico para hidrolizar ATP en ADP, el cual se encuentra comprometido si la perfusión no es normal[76]. Por lo tanto, la hipotermia espontánea posterior a un trauma severo indica que la homeostasis celular se encuentra alterada y que los niveles de almacenamiento de energía se encuentran depletados. De hecho, la existencia de hipotermia en conjunto con acidosis (otro signo de hipoperfusión tisular) y de coagulopatía, son ampliamente conocidos como "la tríada letal"[77].

Otros factores prevenibles que contribuyen a producir hipotermia, son la administración de fluidos fríos y la exposición prolongada en escenarios en que la temperatura ambiente no se encuentra adaptada para reducir el problema. De hecho, como se señaló previamente, un alto porcentaje de pacientes politraumatizados ingresan al servicio de urgencia ya hipotérmicos, producto de las condiciones en que han sido manejados en el escenario prehospitalario[78]. Esta condición suele acentuarse en la sala de recuperación del servicio de urgencia, donde se agregan otras acciones como la remoción de ropas y más infusión de fluidos fríos, lo que muchas veces se complementa con el traslado al servicio de imagenología, donde las 


\section{Tabla 4. Causas de hipotermia en el paciente politraumatizado: se dividen en condiciones que disminuyen la producción de calor corporal o alteran la termorregulación y, condiciones que aumentan las pérdidas de calor. En ambos grupos se pueden identificar causas propias del paciente y del trauma y otras que derivan de condi- ciones del manejo clínico}

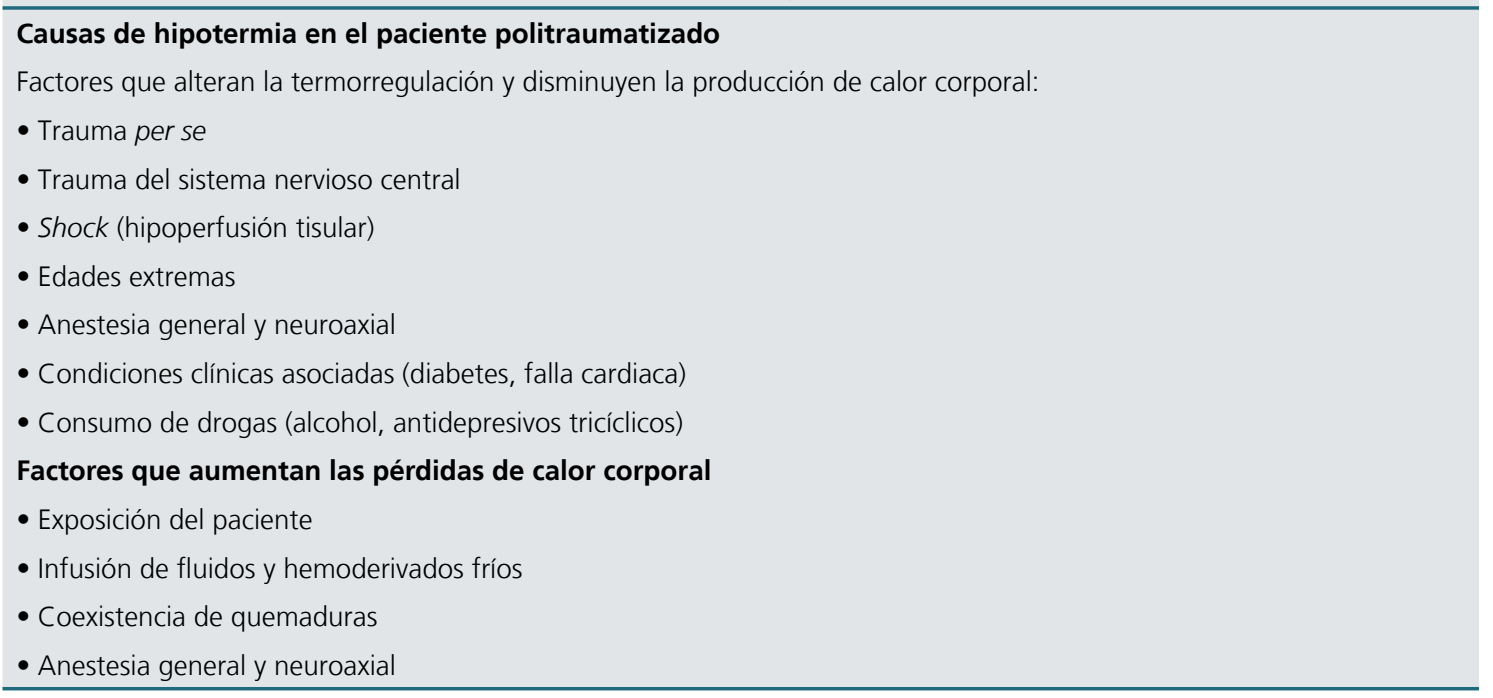

salas (por motivos de funcionamiento de los equipos) suelen mantenerse a temperaturas muy bajas. Si finalmente el paciente es trasladado al pabellón quirúrgico, el anestesiólogo suele recibirlo en hipotermia moderada a severa, producto de conductas clínicas que anteceden a su propio accionar. En consecuencia, en el manejo del paciente politraumatizado no basta con que los equipos anestésicos y quirúrgicos se encuentren comprometidos con el cuidado de la temperatura del paciente, puesto que la temperatura con que ingresará a pabellón dependerá del cuidado que al respecto tengan los profesionales de atención prehospitalaria, de la sala de recuperación de emergencia y del servicio de imagenología.

Este es uno de los motivos por los cuales en respuesta al término "cirugía de control de daños" que se creó para definir una cirugía abreviada que se encarga principalmente de detener los sangrados quirúrgicos y limitar la contaminación, se acuñó un segundo término denominado "resucitación de control de daños" que se desarrolla en paralelo y cuyos objetivos se encuentran definidos para cada uno de los escenarios en que es tratado un paciente politraumatizado (prehospitalario, sala de emergencia, pabellón quirúrgico, unidad de cuidados intensivos). Estos objetivos dicen relación con tiempos máximos de atención, limitación de aporte de fluidos, determinadas terapias farmacológicas, activación de protocolos de transfusión masiva y cuidado obsesivo de la temperatura del paciente[79].

Sin embargo, y en contraste a toda la evidencia disponible, que enfatiza la necesidad de mantener al paciente politraumatizado normotérmico para disminuir la morbilidad y la mortalidad, en la última década han surgido algunas publicaciones que se han planteado si la hipotermia en estos casos "constituye un enemigo o un amigo" [77]. Estas publicaciones que han puesto énfasis en el uso terapéutico de niveles moderados de hipotermia, como un mecanismo de protección de los tejidos del insulto isquémico[80], se basan en el concepto que la hipotermia genera un estado de depresión metabólica que preserva la energía celular, cuando los sustratos y en especial el aporte de oxígeno se encuentra limitado, como es el caso de cualquier estado de shock.

La principal fuente de información respecto a la utilidad de niveles moderados de hipotermia como agente protector, proviene de su uso para evitar daño cerebral anóxico en pacientes resucitados de paro cardiorrespiratorio extrahospitalario[81], sin embargo, es evidente que dicho cuadro clínico es en todo diferente al de un paciente politraumatizado, sobre todo respecto al riesgo de sangrado incoercible y muerte por esta causa, por lo cual los resultados promisorios de un grupo no son extrapolables al otro. Sin embargo, algunos interesantes estudios, aunque con resultados disímiles, se han enfocado en el uso de hipotermia moderada en pacientes con trauma 
craneano grave[82],[83], especialmente aquellos con elevación de la presión intracraneana. En 2004, Polderman[84],[85], realizó un extenso análisis del potencial que posee la hipotermia moderada terapéutica en pacientes con trauma craneano, concluyendo que su aplicación exitosa, depende de una cuidadosa selección de los pacientes (él propone utilizarla en pacientes con presión intracraneana elevada), utilización de protocolos estrictos, monitoreo continuo que evite complicaciones tales como hipovolemia, hipotensión e hiperglicemia y recalentamiento lento y controlado, en especial en pacientes que se han mantenido hipotérmicos por períodos prolongados. En la actualidad, el uso de hipotermia controlada en pacientes politraumatizados aún sigue siendo controvertido, requiriéndose más y mejores estudios bien diseñados para definir su impacto real.

Por el momento sus posibles beneficios no parecen superar sus riesgos, lo que hace que la mayoría de los anestesiólogos la vean más como un "enemigo" que como un "amigo" en el contexto del paciente traumatizado grave, donde sigue primando el temor por enfrentarse a la conocida "tríada letal".

\section{Referencias}

1. Kurz A. Physiology of thermoregulation. Best Pr. Res Clin. Anaesthesiology 2008; 22: 62744. https://doi.org/10.1016/j. bpa.2008.06.004

2. Weirich TL. Hypothermia/warming protocols: why are they not widely used in the OR? AORN Journal 2008; 87: 33344. https://doi.org/10.1016/j. aorn.2007.08.021

3. Carli F, Emery P, Freemantle J. Effect or peroperative normothermia on postoperative protein metabolism in elderly patients undergoing hip arthroplasty. Br J Anesth 1989; 63: 276-82. https://doi.org/10.1093/ bja/63.3.276

4. Kurz A, Sessler DI, Lenhardt R. Perioperative normothermia to reduce the incidence of surgical-wound infection and shorten hospitalization. N Eng J Med 1996; 334: 120916. https://doi.org/10.1056/ NEJM199605093341901

5. Michelson AD, MacGregor $H$, Barnard MR et al. Reversible inhibition of human platelet activation by hypothermia in vivo and in vitro. Thromb Haemost, 1994; 71: 633-40. https://doi. org/10.1055/s-0038-1642495

6. Reed RL, Johnson TD, Hudson JD et al. The disparity between hypothermic coagulopathy and clottin studies. J Trauma 1992; 33: 465-70. https:// doi.org/10.1097/00005373199209000-00022

7. Schmied H, Kurz A, Sessler DI et al. Mild Hypothermia increases blood loss and transfusion requirements during total hip arthroplasty. Lancet 1996; 347: 289-92. https://doi.org/10.1016/ S0140-6736(96)90466-3

8. Frank SM, Fleisher LA, Breslow $\mathrm{MJ}$ et al. Perioperative maintenance of normothermia reduces the incidence of morbid cardiac events: a randomized clinical trial. JAMA 1997; 227: 112734. https://doi.org/10.1001/ jama.1997.03540380041029

9. Leslie K, Sessler DI, Bjorksten A et al. Mild hypothermia alters propofol pharmacokinetics and increases the duration of action of atracurium. Anesth Analg 1995; 80: 1007-14. https:// doi.org/10.1213/00000539199505000-00027

10. Heier T, Caldwell JE, Sessler DI et al. Mild intraoperative hypothermia increases duration of action and spontaneous recovery of vecuronium blockade during nitrous oxide-isoflurane anesthesia in humans. Anesthesiology 1991; 74: 815-19. https:// doi.org/10.1097/00000542199105000-00003
11. Lenhardt R, Kurz A, Sessler DI et al. Intraoperative hypothermia prolong duration of postoperative recovery. Anesthesiology 1995; 83(Supl A): 1114.

12. Lenhardt R, Marker E, Goll V, et al. Mild intraoperative hypothermia prolongs postanesthetic recovery. Anesthesiology 1997; 87: 1318-23. https:// doi.org/10.1097/00000542199712000-00009

13. Just B, Delva E, Camus $Y$ et al. Oxigen uptake during recovery following naloxone. Relationship with intraoperative heat loss. Anesthesiology, 1992; 76: 60-64. https://doi. org/10.1097/00000542199201000-00009

14. Frank SM, Higgins M, Breslow $M$ et al. The catecholamine, cortisol and hemodynamic responses to mild perioperative hypothermia. A randomized clinical trial. Anesthesiology 1995; 82: 83-93. https://doi. org/10.1097/00000542199501000-00012

15. Kurz A, Sessler DI, Narzt E et al. Postoperative hemodynamic and thermoregulatory consequences of intraoperative core hypothermia. J Clin Anesth 1995; 7: 359-66. https://doi.org/10.1016/09528180(95)00028-G

16. Yi J, Liang $H$, Song $R$ et al. 
Maintaining intraoperative normothermia reduces blood loss in patients undergoing major operations: a pilot randomized controlled clinical trial. BMC Anesthesiol 2018; 18: 126. https://doi.org/10.1186/s12871018-0582-9

17. Kiekas P, Theodorakopoulou G, Stefanopoulos N et al. Postoperative hypothermia and mortality in critically ill adults: review and meta-analysis. Australian J Adv Nursing 2011; 28: 60-7.

18. Satinoff E. Neural organization and evolution of thermal regulation in mammals. Science 1978; 201: 16-22. https://doi. org/10.1126/science.351802

19. Jessen C, Feistkorn G. Some characteristics of core temperature signals in the conscious goat. Am J Physiol 1984; 247: R456R464. https://doi.org/10.1152/ ajpregu.1984.247.3.R456

20. Marks LE, Gonzalez RR. Skin temperature modifies the pleasantness of thermal stimuli. Nature 1974; 247: 473-5. https:// doi.org/10.1038/247473a0

21. López M, Sessler DI, Walter K et al. Rate and gender dependence of the sweating, vasoconstriction, and shivering thresholds in humans. Anesthesiology 1994; 80: 780-8. https://doi. org/10.1097/00000542199404000-00009

22. Emerick TH, Ozaki M, Sessler DI et al. Epidural anesthesia increases apparent leg temperature and decreases the shivering threshold. Anesthesiology 1994; 81: 289-98. https:// doi.org/10.1097/00000542199408000-00005

23. Dawkins MJR, Scopes JW. Non-shivering thermogenesis and brown adipose tissue in the human new-born infant. Nature 1965; 206: 201-2. https://doi. org/10.1038/206201b0

24. Hales JRS. Skin arteriovenous anastomoses, their control and role in thermoregulation. In: Johansen K, Burggren W, (eds.) Cardiovascular shunts. Alfred Benzon Symposium 21. Copenhagen, Denmark: Munksgaard, 1985: 433-451. http://hdl.handle .t/102.100.100/275621? index=1

25. Ralley FE, Wynands JE, Ramsay JG et al. The effects of shivering on oxygen consumption and carbon dioxide production in patients rewarming from hypothermic cardiopulmonary bypass. Can J Anaesth 1988; 35 : 332-7. https://doi.org/10.1007/ BF03010851

26. Annadata R, Sessler DI, Tayefeh $F$ et al. Desflurane slightly increases the sweating threshold, but produces marked, nonlinear decreases in the vasoconstriction and shivering thresholds. Anesthesiolo 1995; 83: 1205-1211. https:// doi.org/10.1097/00000542199512000-00011

27. Kurz A, Go JC, Sessler DI et al. Alfentanil slightly increases the sweating threshold and markedly reduces the vasoconstriction and shivering thresholds. Anesthesiology 1995; 83: 293-9. https:// doi.org/10.1097/00000542199508000-00009

28. Matsukawa T, Kurz A, Sessler DI et al. Propofol linearly reduces the vasoconstriction and shivering thresholds. Anesthesiology 1995; 82: 1169-80. https:// doi.org/10.1097/00000542199505000-00012

29. Xiong J, Kurz A, Sessler DI et al. Isoflurane produces marked and nonlinear decreases in the vasoconstriction and shivering thresholds. Anesthesiology 1996; 85: 240-5. https://doi. org/10.1097/00000542199608000-00003

30. Hynson JM, Sessler DI, Moayeri A et al. Absence of nonshivering thermogenesis in anesthetized adult humans. Anesthesiology 1993; 79: 695-703. https:// doi.org/10.1097/00000542199310000-00010

31. Plattner O, Semsroth M, Sessler DI et al. Lack of nonshivering thermogenesis in infants anesthetized with fentanyl and propofol. Anesthesiology 1997; 86: 772-7. https:// doi.org/10.1097/00000542199704000-00006

32. Kurz A, Xiong J, Sessler DI et al. Desflurane reduces the gain of thermoregulatory arteriovenous shunt vasoconstriction in humans. Anesthesiology 1995; 83: 1212-19. https:// doi.org/10.1097/00000542199512000-00012

33. Matsukawa T, Sessler DI, Sessler AM et al. Heat flow and distribution during induction of general anesthesia. Anesthesiology 1995; 82: 662-73. https:// doi.org/10.1097/00000542199503000-00008

34. Kurz A, Sessler DI, Christensen $R$ et al. Heat balance and distribution during the core-temperature plateau in anesthetized humans. Anesthesiology 1995; 83: 491-9. https:// doi.org/10.1097/00000542199509000-00007

35. Sessler DI. Mild perioperative hypothermia. N Engl J Med 1997; 336: 1730-7. https://doi.org/10.1056/ NEJM199706123362407

36. Kirkland KB, Briggs JP, Trivette SL et al. The impact of surgical-site infections in the 1990s: attributable mortality, excess length of hospitalization and extra costs. Infect Control Hosp Epidemiol 1999; 20: 725-30. https://doi. org/10.1086/501572

37. Zimlichman E, Henderson D, Tamir $\mathrm{O}$ et al. Health care-associated infections: a meta-analysis of cost and financial impact on the U. S. health system. JAMA 
Intern Med 2013; 173: 2039-46. https://doi.org/10.1001/jamainternmed.2013.9763

38. Anderson DJ, Podgorny K, Berrios-Torres $\mathrm{S}$ et al. Strategies to prevent surgical site infection in acute care hospitals: 2014 Update. Infect Control Hosp Epidemiol 2014; 35: 605-27. https://doi.org/10.1086/676022

39. Berrios-Torres S, Umscheid C, Bratzler D et al. Centers for disease control and prevention guideline for the prevention of surgical site infection, 2017. JAMA Surg 2017; 152: 784-91. https://doi.org/10.1001/jamasurg.2017.0904

40. Resolución Exenta No 894 que aprueba la Norma General Técnica No 190 para la Prevención de Infección de Herida Operatoria, 05 de julio de 2017, Subsecretaría de Redes Asistenciales, Ministerio de Salud, Chile.

41. Torossian, A. Survey in intraoperative temperatur e management in Europe. Eur J Anaesthesiol 2007; 24: 66875. https://doi.org/10.1017/ S0265021507000191

42. Echeverry P, Rincón D, Monroy A et al. Survey about attitudes on perioperative temperature monitoring and thermal protection in Colombia. Rev Colomb Anestesiol 2016; 44: 282-91. https://doi.org/10.1016/j. rcae.2016.08.002

43. Standards for Basic Anesthetic Monitoring. Committee on Standards and Practice Parameters (CSPP) American Society of Anesthesiologists. Last Amended: October 28, 2015. en: https://www.asahq.org/standards-and-guidelines/standardsfor-basic-anesthetic-monitoring

44. Gelb AW, Morriss WW, Johnson W et al. World Health Organization-World Federation of Societies of Anaesthesiologists (WHO-WFSA) International standards for a safe practice of anesthesia. Can J Anaesth 2018; 65: 698-708. https://doi. org/10.1007/s12630-018-11115

45. Recomendaciones Clínicas de la Sociedad de Anestesiología de Chile sobre Disponibilidad y uso de monitorización perioperatoria. Comité de Recomendaciones Clínicas de la Sociedad de Anestesiología de Chile. Actualizada en 2017. en: https://www.sachile.cl/recomendaciones-clinicas/

46. Sessler DI. Temperature monitoring and perioperative thermoregulation. Anesthesiology 2008, 109: 318-38. https://doi.org/10.1097/ ALN.0b013e31817f6d76

47. Cork RC, Vaughan RW, Humphrey LS. Precision and accuracy of intraoperative temperature monitoring. Anesth Analg 1983, 62: 211-4. https:// doi.org/10.1213/00000539198302000-00016

48. Eshraghi $Y$, Nasr V, ParraSánchez I et al. An evaluation of zero-heat-flux cutaneous thermometer in cardiac surgical patients. Anesth Analg 2014, 119: 543-9. https://doi.org/10.1213/ ANE.0000000000000319

49. Morris RH. Operating room temperature and the anesthetized, paralyzed patient. Arch Surg 1971; 102: 95-7. https://doi.org/10.1001/archsurg.1971.01350020005002

50. Sessler DI, McGuire J, Sessler AM. Perioperative thermal insulation. Anesthesiology 1991; 74: 875-9. https:// doi.org/10.1097/00000542199105000-00012

51. Sessler DI, Schroeder M. Heat loss in humans covered with cotton hospital blankets. Anesth Analg 1993; 77: 73-7. https:// doi.org/10.1213/00000539199307000-00014

52. Sessler DI. Consequences and treatment of perioperative hypothermia. Anesth Clin North Am 1994; 12: 425-56.

53. Kurz A, Kurz M, Poeschl G et al. Forced-air warming maintains intraoperative normothermia better than circulating-water mattresses. Anesth Analg 1993; 77: 89-95. https:// doi.org/10.1213/00000539199307000-00018

54. Maisel W. Information about the Use of forced air thermal regulating systems - Letter to health care providers. 2017. Food and Drugs Administration. en: https:// www.fda.gov/medical-devices/ letters-health-care-providers/ information-about-use-forcedair-thermal-regulating-systemsletter-health-care-providers

55. Deriaz H, Fiez N, Lienhart A. Influence d'un filtre hygrophobe ou dùn humidificateurréchauffeur sur l'hypothermie peropératoire. Ann Fran Anesth Réanim 1992; 11, 145-9. https://doi.org/10.1016/S07507658(05)80005-X

56. Kurz A. Prevention and treatment of perioperative hypothermia. Curr Anaesth Crit Care 2001; 12: 96-102. https:// doi.org/10.1054/cacc.2001.0332

57. Yoshie T, Utsumi I. The efficacy of prewarming on post-induction core temperature and thermoregulatory response under general anesthesia. Eur J Anaesth 2012, 29: 30. https:// doi.org/10.1097/00003643201206001-00099

58. Caio R, Siaulys M, Vieira J et al. Perioperative warming with a thermal gown prevents maternal temperature loss during elective cesarean section. A randomized clinical trial. Braz J Anest 2016; 66: 4515. https://doi.org/10.1016/j. bjane.2014.12.007

58. Kwang-seob Sh, Guie YL, Eun $\mathrm{HCh}$ et al. Effect of short- 
term prewarming on body temperature in arthroscopic shoulder surgery. Anesth Pain Med, 2017; 12: 388-93. https://doi.org/10.17085/ apm.2017.12.4.388

59. Shenoy L, Krishna HM, Kalyan N et al. A prospective comparative study between prewarming and cowarming to prevent intraoperative hypothermia. J Anaesthesiol Clin Pharmacol 2019; 35: 231-5. https://doi.org/10.4103/ joacp.JOACP_353_17

60. Andrzejowski J, Hoyle J, Eapen $G$ et al. Effect of prewarming on post-induction core temperature and the incidence of inadvertent perioperative hypothermia in patients undergoing general anaesthesia. $\mathrm{Br} J$ Anaesth 2008; 101: 627-31. https://doi. org/10.1093/bja/aen272

61. Sun Z, Honar H, Sessler DI et al. Intraoperative core temperature patterns, transfusion requirement and hospital duration in patients warmed with forced air. Anesthesiology 2015; 122: 276-85. https://doi.org/10.1097/ ALN.0000000000000551

62. Woodson LC, Sherwood ER, Kinsky $M$ et al. Anesthesia for burned patients. Herndon DN (eds) Total Burn Care, 5th edition. Edinburgh, Elsevier, 2018, pp 131-157. https://doi. org/10.1016/B978-0-323-476614.00013-7

63. Bittner E, Shank E, Woodson L et al. Acute and perioperative care of the burn-injured patient. Anesthesiology 2015; 122 : 448-64. https://doi.org/10.1097/ ALN.0000000000000559

64. Alvarado R, Chung KK, Cancio LC et al. Burn resuscitation. Burns 2009; 35: 4-14. https://doi.org/10.1016/j. burns.2008.03.008

65. Oda J, Kasai K, Noborio M et al. Hypothermia during burn surgery and postope- rative acute lung injury in extensively burned patients. J Trauma, 2009; 66: 152530. https://doi.org/10.1097/ TA.0b013e3181a51f35

66. Hardy JF, Moerloose Ph, Samama ChM. Massive transfusion and coagulopathy: pathophysiology and implications for clinical management. Can J Anesth 2006; 53: S40-S57. https://doi. org/10.1007/BF03022251

67. Yoshihara H, Yamamoto $\mathrm{T}$, Mihara $\mathrm{H}$. Changes in coagulation and fibrinolysis occurring in dogs during hypothermia. Thromb Res 1985; 37: 503-12. https://doi.org/10.1016/00493848(85)90096-9

68. Rohrer MJ, Natale AM. Effect of hypothermia on the coagulation cascade. Crit Care Med 1992; 20: 1402-5. https:// doi.org/10.1097/00003246199210000-00007

69. Pina-Cabral JM, Ribeiro-da-Silva A, Almeida-Dias A. Platelet sequestration during hypothermia in dogs treated with sulphinpyrazone and ticlopidine - reversibility accelerated after intra-abdominal rewarming. Thromb Haemost 1985; 54: 838-41. https://doi. org/10.1055/s-0038-1660144

70. Valeri $C R$, Khabbaz K, Khuri SF et al. Effect of skin temperature on platelet function in patients undergoing extracorporeal bypass. J Thorac Cardiovasc Surg 1992; 104: 108-16. https://doi.org/10.1016/S00225223(19)34842-1

71. Michelson AD, MacGregor $H$, Barnard MR et al. Reversible inhibition of human platelet activation by hypothermia in vivo and in vitro. Thromb Haemost 1994; 71: 633-40. https://doi. org/10.1055/s-0038-1642495

72. Hess J, Brohi K, Dutton R et al. The coagulopathy of trauma: a review of mechanisms. J Trauma 2008; 65: 748-54. https://doi.org/10.1097/

TA.0b013e3181877a9c

73. Brohi $K$, Singh J, Heron $M$ et al. Acute traumatic coagulopathy. J Trauma, 2003; 54: 1127-30. https://doi.org/10.1097/01. TA.0000069184.82147.06

74. Mathews J, Praveen K. The challenge in management of hemorrhagic shock in trauma. Med J Armed Forces India 2014; 70: 163-9. https://doi.org/10.1016/j. mjafi.2014.03.001

75. Helm M, Lampl L, Hauke J et al. Accidental hypothermia in trauma patients. Is it relevant to preclinical emergency treatment? Anaesthesist 1995; 44: 101-7.

76. Tsuei BJ, Kearney PA. Hypothermia in the trauma patient. Injury, 2004; 35: 7-15. https:// doi.org/10.1016/S00201383(03)00309-7

77. Kheirbek T, Kochanek A, Alam $\mathrm{H}$. Hypothermia in bleeding trauma: a friend or a foe? Scand J of Trauma Res Emerg Medicine 2009; 17,65. Disponible en: http://www.sjtrem.com/ content/17/1/65. https://doi. org/10.1186/1757-7241-17-65

78. Gregory JS, Flancbaum L, Townsend MC et al. Incidence and timing of hypothermia in trauma patients undergoing operations. J Trauma 1991; 31: 795-800. https:// doi.org/10.1097/00005373199106000-00009

79. Giannoudi M, Harwood P. Damage control resuscitation: lessons learned. Eur J Trauma Emerg Surg 2016; 42: 273-82. https://doi.org/10.1007/s00068015-0628-3

80. Alzaga AG, Cerdan M, Varon J. Therapeutic hypothermia. Resuscitation, 2006; 70: 369380. https://doi.org/10.1016/j. resuscitation.2006.01.017

81. The Hypothermia after Cardiac Arrest Study Group. Mild therapeutic hypothermia to improve 
the neurologic outcome after cardiac arrest. N Engl J Med, 2002; 346: 549-56. https://doi. org/10.1056/NEJMoa012689

82. Marion DW, Penrod LE, Kelsey SF, et al. Treatment of traumatic brain injury with moderate hypothermia. $\mathrm{N}$ Engl J Med 1997; 336: 5406. https://doi.org/10.1056/ NEJM199702203360803

83. Harris OA, Colford JM Jr, Good
MC et al. The role of hypothermia in the management of severe brain injury: a meta-analysis. Arch Neurol 2002; 59: 1077-83. https://doi.org/10.1001/archneur.59.7.1077 